\title{
Spectral analysis of mean flow and turbulence forced by waves in a horizontally homogeneous zone of the Iroise sea
}

\section{A comparison with current times series measured by high-frequency radar}

\author{
Guillaume Simon ${ }^{1, *}$, Franck Dumas ${ }^{1}$ and Thomas Duhaut $^{1}$ \\ ${ }^{1}$ IFREMER DYNECO-PHYSED, BP70, 29280 Plouzané, France \\ *: Corresponding author : Guillaume Simon, email address : gui.simon@gmail.com
}

\begin{abstract}
:
The 1D version of the Model for Applications at Regional Scale is used to parameterize the effects of sea surface waves in 2D in a horizontally homogeneous offshore zone of the Iroise sea. Here we present the first simulation of the Iroise sea including sea surface waves forcing, and more generally, the first study of a boundary layer including the Hasselmann force with a tidal wave. We use a single equation turbulence closure based on a non-local diagnosis for energetic and dissipation length scales. The turbulent energy flux at the surface due to whitecaps and the Hasselmann force induced by Stokes drift are assessed using the whole sea surface waves spectrum given by the Wave Watch Third generation model. The ability of the parameterization to reproduce surface currents over a period of 1 year (2007) is tested with high frequency radar using spectral and time-frequency analysis. One problem with 1D modelling, corresponding to overestimation of current oscillating at inertial frequency is illustrated by comparing $1 \mathrm{D}$ and $3 \mathrm{D}$ simulations. We found an overall improvement by including the Hasselmann force mainly within the bandwidth of less than one cycle per day to one cycle per day for surface currents. Turbulence is induced by whitecaps decaying rapidly below the ocean surface but the mixed layer below $40 \mathrm{~m}$ is deeper due to waves breaking on the sea surface.
\end{abstract}

Keywords : Ocean turbulence - Waves - Stokes drift - Iroise sea - MARS - High-frequency radar OSCR 


\section{Introduction}

The Iroise Sea is a part of the Atlantic Ocean located west of Brittany in France (fig. 1) along the path of low-pressure atmospheric systems. This is an area of shallow water with a mean depth of about $110 \mathrm{~m}$. The coast exhibits fractal complexity. Because of its location and coastal configuration, it is a particularly complex and interesting area in terms of meteorological, hydrodynamics, thermodynamics, waves and biological activities. Interactions between tidal waves, coastline irregularities and bathymetry produce currents of up to $4 \mathrm{~m} / \mathrm{s}$ during spring tides near islands and capes (Le Duff and Hily, 1999). When storms and swell generated by the mid-latitude local pressure atmospheric systems that cross the Atlantic Ocean from west to east reach the area, shipping can become extremely dangerous. In addition, the fact that the Iroise Sea is an area of intense maritime traffic between the Atlantic Ocean and the English Channel implies a high risk of oil spills and hazardous substance releases. That is why a better understanding of the sea surface process is of paramount importance in this region.

The Iroise sea has been intensively studied since the late 1970s, but because here we are only interested in offshore conditions, we will not provides details on all the physical, chemical or bio-geochemical observations made in the area with moorings and fixed stations which can be found in Le Fevre and Grall (1970), Pingree et al (1977), Mariette (1983), Le Corre and Mariette (1985), Birrien (1987) and Le Boyer et al (2009). Numerical simulations of the Iroise sea with different kind of model have been performed and are described in Altazin-Pichon (1981), Mariette et al (1982), Mariette (1983), Mariette and Le Cann (1985), Orbi and Salomon (1988), Muller et al (2007), Cambon (2008), Muller (2008), Muller et al (2009) and Muller et al (2010). Some theoretical studies about baroclinic instability can be found in Pavec et al (2005), Pavec (2007). The dominant feature of the summer season in the 
Iroise sea is the presence of a thermal front (Le Fevre and Grall, 1970; Pingree et al, 1977; Mariette et al, 1982; Le Corre and Mariette, 1985; Mariette and Le Cann, 1985; Le Boyer et al, 2009). This thermal front separates tidally mixed coastal waters from the thermally stratified offshore waters. In figure 1 the thermal front is located between point A and point B and is roughly south-north oriented. Point A is stratified and point B is well mixed.

Due to tide, latitude and thermal stratification, a wide range of oscillatory phenomena occur in the coastal Iroise sea. Frequencies of some of them are presented in table 1. Due to these wave dominated dynamics, spectral analysis was an appropriate tool for our study. At point A, between January 1, 2004 and December 31, 2008, the WW3 model gave a time averaged $H s$ of $2.4 \mathrm{~m}$ and a time averaged period of $9.9 s$ corresponding to a peak frequency of $0.101 \mathrm{~Hz}$. The $\mathrm{Hs}$ maximum during this period was $12.2 \mathrm{~m}$. There was a spectral gap between the frequency of the current and the frequency of the sea surface waves, the oscillation of the sea surface waves was approximately 300 times faster than that of the inertial gravity waves.

As we were mainly interested in increasing the accuracy of surface ocean current forecasting, we used high frequency radar previously described in Ardhuin et al (2009) to validate our parameterization. 


\begin{tabular}{|l||l|l|}
\hline \multicolumn{1}{l||}{} & $\ldots$ & $\ldots$ \\
& $f_{M_{8}}=7.73 \mathrm{cpd}$ & $T_{M_{8}}=3.11$ hours \\
& $f_{M_{6}}=5.80 \mathrm{cpd}$ & $T_{M_{6}}=4.14$ hours \\
& $f_{M_{4}}=3.86 \mathrm{cpd}$ & $T_{M_{4}}=6.21$ hours \\
& $f_{M_{2}}=1.93 \mathrm{cpd}$ & $T_{M_{2}}=12.42$ hours \\
& $f_{K_{1}}=1.00 \mathrm{cpd}$ & $T_{K_{1}}=23.93$ hours \\
& $f_{M f}=0.07 \mathrm{cpd} \approx 2.1 \mathrm{cpm}$ & $T_{M f}=13.66$ days \\
& $f_{M_{m}}=0.04 \mathrm{cpd} \approx 1.1 \mathrm{cpm}$ & $T_{M_{m}}=27.56$ days \\
\hline Tide & $\ldots$ & $\ldots$ \\
\hline GWs & $\left.\left.f_{G W s} \in\right] 0, O(25.92)\right] \mathrm{cpd}$ & $T_{G W s} \in[$ O(55.56), $\infty[$ minutes \\
\hline IGWs & $\left.\left.f_{I W s} \in\right] 0,1.50336\right] \mathrm{cpd}$ & $T_{I W s} \in[15.96, \infty[$ hours \\
\hline SWs & $\left.\left.f_{I G W s} \in\right] 0, O(25.92)\right] \mathrm{cpd}$ & $T_{I G W s} \in[O(55.56), \infty[$ minutes \\
\hline
\end{tabular}

Table 1 Frequencies of mechanisms in the Iroise sea at point A (fig. 1). $M_{2}$ is the main lunar semi-diurnal,

$M_{4}$ and $M_{6}$ are shallow water over-tides of principal lunar harmonic, $M_{8}$ is a shallow water eighth diurnal harmonic, $K_{1}$ is a lunar diurnal harmonic, $M_{f}$ is a lunisolar fortnightly harmonic, $M_{m}$ is a lunar monthly harmonic, $I W s$ denote inertial waves, $G W s$ denote internal gravity waves, $I G W s$ denote mixed internal inertiogravity waves and $S W s$ denote sea surface waves and related time averaged values of the peak frequency. 


\section{Oceanic data and method}

In this section, we present the experimental data used for validation at the location considered in this study. High frequency radar was used to measure the surface velocity current.

\subsection{High frequency (H.F.) radar data}

In 2005, two coastal H.F. radars were deployed, one at Porspoder (point $R_{\text {north }}$ in fig. 1 ) and the other at Cléden-Cap-Sizun (point $R_{\text {south }}$ in fig. 1) to measure the sea surface currents in the area in a near-real-time experiment (Cochin, 2006; Mariette et al, 2006).

Basically what the H.F. radar measures (denoted $\hat{U}_{\text {Radar }}$ ) is the sum of the quasi-Eulerian velocity $U_{\text {Radar }}$ and part of the Stokes drift (Stokes, 1847) $U_{\text {Stokes }}^{B}$. The Stokes drift $U_{\text {Stokes }}^{B}$ is recomposed by waves at a frequency lower than the Bragg frequency (Ardhuin et al, 2009).

$$
\hat{U}_{\text {Radar }}=U_{\text {Radar }}+U_{\text {Stokes }}^{B}
$$

It was demonstrated by Ardhuin et al (2009) that it is more accurate to compute the Stokes contribution $U_{\text {Stokes }}^{B}$ with WW3 rather than to deduce it from H.F. radar. We thus use the numerical wave model WW3 (Tolman, 2007) with modifications (Roland et al, 2008; Ardhuin et al, 2009) to compute and remove the Stokes drift $U_{\text {Stokes }}^{B}$ from the current measured by H.F. radar $\hat{U}_{R a d a r}$ and we compare the current $U_{\text {Radar }}$ with numerical simulations at one location. Ocean surface current radar (OSCR) measurement is a complicated process and the accuracy of the data is influenced by many phenomena. As recalled by Davies et al (2001) some of these sources of bias in OSCR measurement are the non-homogeneity of the wave field, the distorted antennae, the reflexion of the coastline topography, sea states, and electromagnetic parasites ... Fortunately for us, our study area is an offshore zone where wave fields are relatively homogeneous (see the Stokes drift in fig. 1) and, according to Ardhuin 


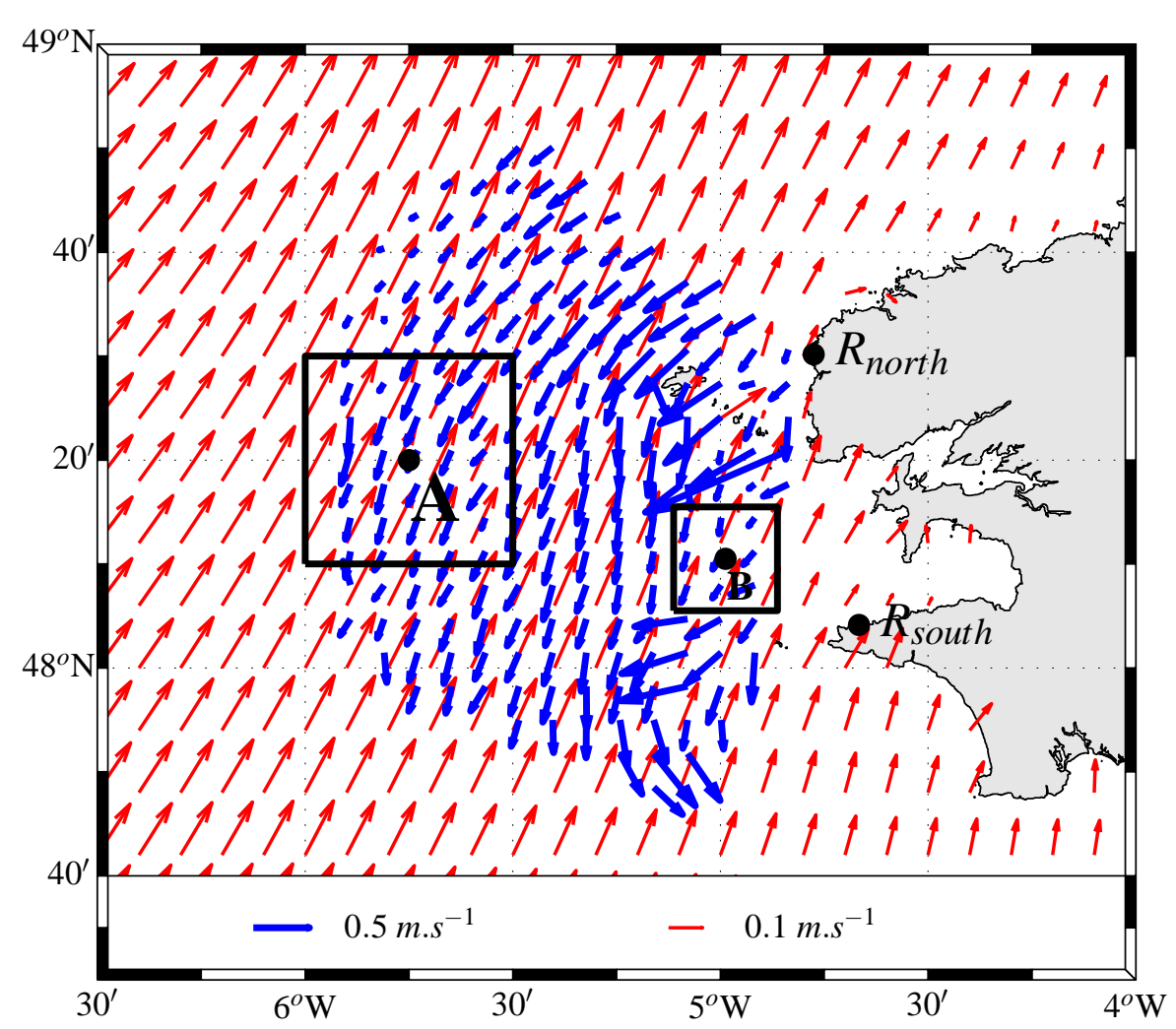

Fig. 1 Map of the Iroise sea off the west coast of France showing the Stokes drift $\mathbf{U}_{\text {Stokes }}$ (in red) on February 15 2007, at 18:00 UTC, estimated with the numerical wave WW3 model, and the instantaneous surface current measured by H.F. radar (in blue) at Porspoder $\left(R_{\text {north }}\right)$ and Cléden-Cap-Sizun $\left(R_{\text {south }}\right)$. The large black squares around point $\mathrm{A}$ and point $\mathrm{B}$ show the areas where the radar data was compiled to provide the times series analysed here. Point A is stratified whereas point B is located in an unstratified zone. Measurements for the entire square were available for more than $80 \%$ of the 20 minute records, and $99 \%$ for the area east of $5^{\circ} 35^{\prime} \mathrm{W}$. The partial radar coverage around point A was due to strong wave conditions, with $H s>6 \mathrm{~m}$ (Ardhuin et al, 2009).

et al (2009), the radar antenna lobe patterns were verified using both in situ transmitters and a novel technique based on the analysis of radio interference. Here we use the same H.F. radar data and processing as in Ardhuin et al (2009) and a full analysis of the error implied by H.F. radar can be found in their study. The OSCR error was estimated at an average of 
$10-15 \mathrm{~cm} / \mathrm{s}$ by Lewis et al (1998) and was $<7 \mathrm{~cm} / \mathrm{s} 50 \%$ of the time according to Paduan and Rosenfeld (1996). In the present study, the OSCR error was estimated at $0.3 \%$ of $U_{10}$ by Ardhuin et al (2009). For example, the wind at a height of $10 \mathrm{~m}$ blowing at $50 \mathrm{~km} / \mathrm{h}$ means an error of the order of $4.1 \mathrm{~cm} / \mathrm{s}$.

\subsection{Location studied and method}

To compare model parameterization and observations, we use only point A (fig. 1). Ardhuin et al (2009) who identified a quasi 2D horizontally homogeneous area at this location. This is especially relevant because we want to test the effect of offshore parameterization of sea surface waves forcing on current.

We obtained a vector time series with H.F. radar data after removing the contribution of Stokes drift, applying a time median filter, and averaging over space (black square around point A in fig. 1) and over time. The magnitude of the current time series is shown in fig. 2. Like in Ardhuin et al (2009), OSCR data were averaged in space and time, each point in the time series is the combination of about 30 range cells and nine time intervals, i.e. 180 independent velocity measurements using the full radar range. Because of this data processing, for an $11 \mathrm{~cm} / \mathrm{s}$ uncertainty on the original measurement, the expected r.m.s. error on the velocity components is thus less than $1 \mathrm{~cm} / \mathrm{s}$. In order to extract information from this time series, we used rotary spectra (Gonella, 1972). Rotary spectral analysis gives both the frequency distribution of the signal and an indication of its rotation tendencies. The positive frequencies correspond to counter-clockwise (CCW) motions and the negative frequencies correspond to clockwise $(\mathrm{CW})$ motions, this being the Coriolis rotation like in the Northern hemisphere. The negative frequency can be plotted on the positive frequency axis for easy comparison of circular polarization (fig. 3). The black rectangles in fig. 3, fig. 
4, fig. 5, fig. 10, fig. 11 and fig. 13 provide information about statistical accuracy. The height of the rectangle is the $95 \%$ confidence interval (Emery and Thomson, 2001) and the width of the rectangle is the frequency resolution.

At point $\mathrm{A}, \mathrm{CW}$ motion (fig. 3) which is driven by the Coriolis force, is more energetic. The instantaneous measurements of the radar are dominated by tidal currents $M_{2}$. Motions with frequencies ${ }^{1}$ less than $1.75 \mathrm{cpd}$ are dominated by near-inertial motions of around $1.5 \mathrm{cpd}$.

To compare inertial movements in stratified and well-mixed areas, we also built a time series at point B where only H.F. radar data were used. We do not compare them with the one-dimensional numerical model because assumptions of horizontal homogeneity were not met.

Six hourly atmospheric ARPEGE data were used and linearly interpolated to force the 1D model. Because we don't have variability shorter than 6 hours in the atmospheric forcing, we limited our study to periods longer than 9.5 hours $(2.5 \mathrm{cpd})$ and ignored the high frequency part of the spectrum. We now present the numerical model and its parameterization.

\footnotetext{
1 We have used the acronym cpd to indicate cycles per day.
} 


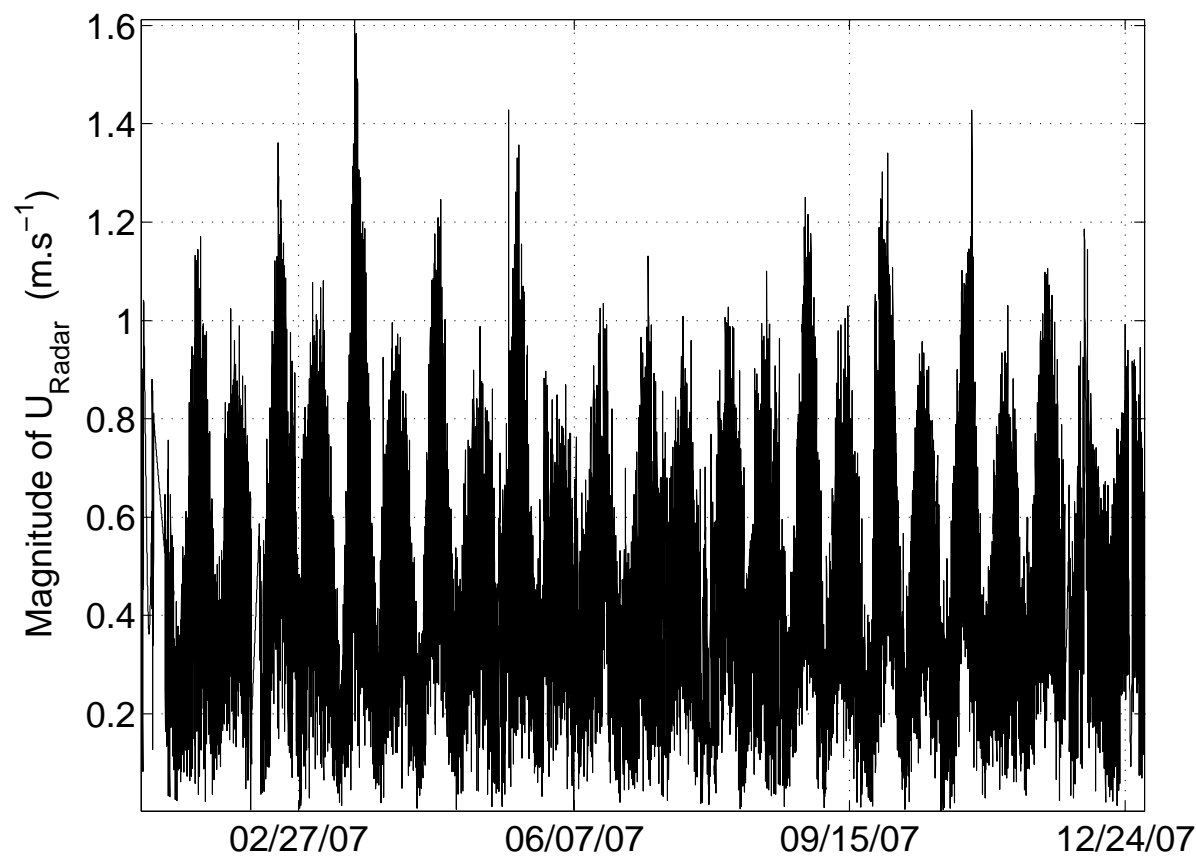

Fig. 2 Time series of H.F. radar velocity magnitude during the full year 2007 at point A as defined in fig. 1. This time series has a mean value of $47 \mathrm{~cm} \cdot \mathrm{s}^{-1}$ and a standard deviation of $23 \mathrm{~cm} \cdot \mathrm{s}^{-1}$. The maximum was reached on March 19, 2007 with $161 \mathrm{~cm} \cdot \mathrm{s}^{-1}$ by due to the combination of strong tides and strong sea state conditions with waves higher than $6 \mathrm{~m}$. 


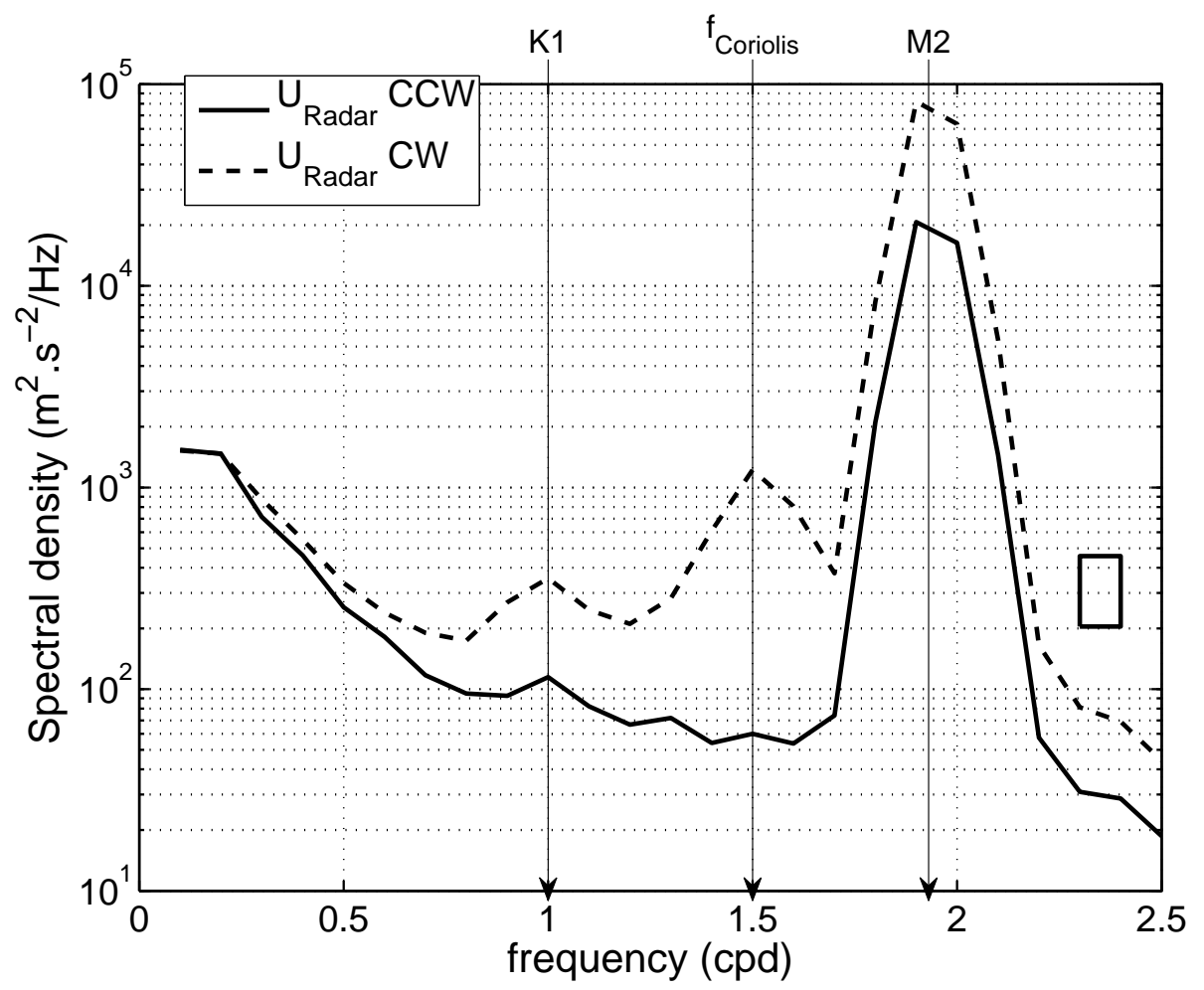

Fig. 3 Rotary power spectra of the quasi-Eulerian current (magnitude is shown in fig. 2) measured by H.F. radar at point A (fig. 1). Clockwise (CW) motions are shown with dashed lines and counter-clockwise (CCW) motions are shown with solid lines. The spectra were estimated using 264 hour long half-overlapping segments over the parts of the time series with no gaps. The number of degrees of freedom used was 192 and the spectral resolution was $0.09 \mathrm{cpd}$ (horizontal size of the rectangle). At the $95 \%$ confidence level the relative error was linked to the vertical size of the rectangle. 


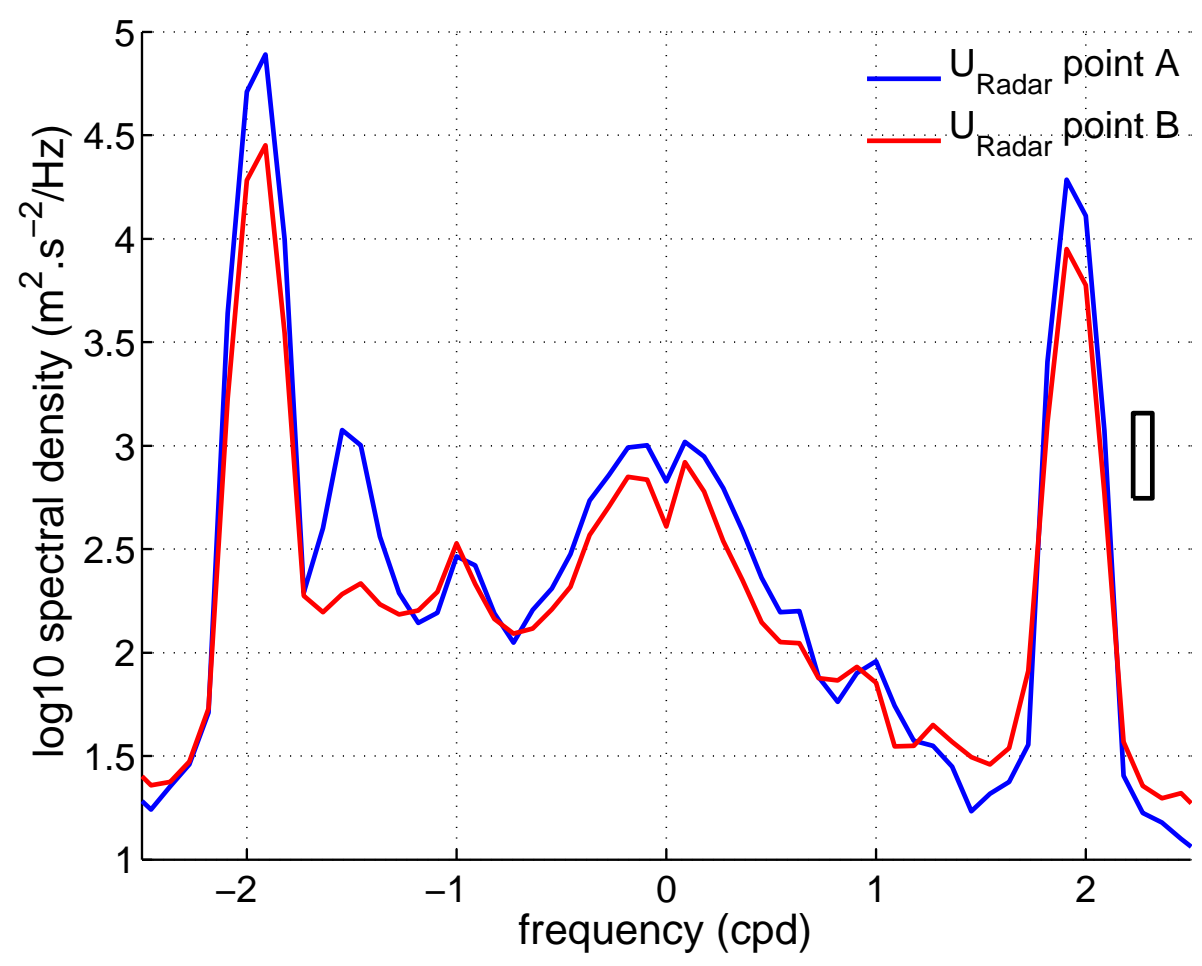

Fig. 4 Rotary spectra of quasi-Eulerian current measured by H.F. radar at Point A and point B (fig. 1). Time series were built by combining the gaps at point A and point B to obtain the same degree of freedom in each time series. The spectra were estimated using 264 hour long half-overlapping segments over the parts of the time series with no gaps. The number of samples taken was 45 and equivalent degrees of freedom of 138 at a spectral resolution of $0.09 \mathrm{cpd}$ (horizontal size of the rectangle). At the $95 \%$ confidence level the relative error was linked to the vertical size of the rectangle. Negative frequencies are clockwise (Coriolis like) polarized motions and positive frequencies are counter-clockwise polarized motions. 


\section{1D vertical models and parametrization of sea surface waves}

As seen in section 2.2, vwe assumed that the wave, velocity and turbulent properties were horizontally uniform to meet 1D assumptions (Ekman, 1905). We did not compute salinity because its variations are very weak compared with thermal variations (Birrien, 1987). The computational variables are velocity $\mathbf{U}$, temperature $T$ and turbulent kinetic energy $k$. Our coordinate system was chosen as the surface at $z=H$ and the bed at $z=0$, where $H$ is water depth. We start by recalling the equations for what we call mean quantities $(\mathbf{U}$ and $T)$ followed by the equation for variations in turbulence kinetic energy $(k)$.

3.1 Equation for the mean quantities $\mathbf{U}$ and $T$

\subsubsection{Equations for zonal $U$ and meridional $V$ mean velocities}

Starting from the primitive equation, we assumed that the diffusion of momentum by viscosity is negligible compared to the transport of momentum due to turbulence. As the tide is the main energetic motion at point A (fig. 3) and we could not work on residual current only, as done in many other studies (table 2) we incorporated tide in the 1D vertical water column model. The spatial variation of the tidal pressure gradient $-g \nabla_{\mathbf{H}} \zeta$ was assumed to be larger than the zone we are looking for. The equation we used is exactly the same as that used by Rascle et al (2006), Rascle (2007), Rascle and Ardhuin (2009) and Ardhuin et al (2009) except for the tidal pressure term. To get this equation, we need to approximate the horizontal homogeneity of the velocity and temperature field. The equation is then:

$$
\frac{\partial \mathbf{U}}{\partial t}=-f_{\Omega} \mathbf{e}_{z} \wedge \mathbf{U}+\mathbf{F}_{H}-\frac{\partial}{\partial z} \overline{\mathbf{u} w}-g \nabla_{\mathbf{H}} \zeta
$$

where $\mathbf{U}=(U, V, 0)$ is the quasi-Eulerian velocity, $\mathbf{e}_{z}$ is a vertical unit vector pointing to zenith, $\mathbf{U}_{\text {Stokes }}=\left(U_{\text {Stokes }}, V_{\text {Stokes }}, 0\right), \mathbf{u}=(u, v, w)$ is the random turbulent velocity fluctua- 
tion implicated in $\overline{\mathbf{u} w}$ the part of the Reynolds stress tensor, $\nabla_{\mathbf{H}}$ is the $2 \mathrm{D}$ horizontal gradient operator, $\zeta$ is the slope of the free surface of the barotopic assumption and $\mathbf{F}_{H}$ is the Hasselmann force. Note that the Hasselmann force is defined by (Hasselmann, 1970) as:

$$
\mathbf{F}_{H}=-f_{\Omega} \mathbf{e}_{z} \wedge \mathbf{U}_{\text {Stokes }}
$$

Equation 2 is under certain approximation ((Xu and Bowen, 1994; Ardhuin et al, 2008b)) compatible with the generalized Lagrangian mean (GLM, Andrews and McIntyre (1978); Groeneweg and Klopman (1998); Groeneweg (1999); Ardhuin et al (2008b)) framework. Note that $U$ and $U_{\text {Stokes }}$ are $U_{L}$ and $p$ in the notation of Andrews and McIntyre (1978) and that they are evaluated at a slightly displaced vertical position Mcintyre (1988). As recalled by Rascle et al (2006), this formalism can also be obtained by subtracting the wave pseudomomentum from the total momentum equation provided by ?. Despite the fact that the 1D model of Groeneweg and Klopman (1998); Groeneweg (1999) shows that the correlations between the wave pseudo-momentum and the shear and the wave-induced Reynolds stress have a pronounced effect on the distribution of the mean horizontal velocity over depth, we chose to not include it in our first approach. Because the lowest order of the vertical Stokes drift component is given (see Ardhuin et al (2008a)), by the horizontal divergence of $\left(U_{\text {Stokes }}, V_{\text {Sokes }}\right)$ since our flow is assumed to be horizontally homogeneous, we disregarded the vertical component of the Stokes drift. And shown by Rascle et al (2006) the contribution to the wave induced Reynolds stress to the total energy input is only $10 \%$ of the that imputed by breaking waves, so in our first approach we chose to not include it in our model.

Among several methods (table 2) to include tidal effects, we chose to account for these effects as a horizontal external pressure gradient (fourth term on the right in eq. 2). The tidal pressure gradient was computed by finite differences in Sea Surface High (SSH) using 
the CST France tidal model from Service Hydrographie et Océanographie de la Marine

(SHOM) with the 115 main harmonic constituents (Le Roy and Simon, 2003).

\begin{tabular}{|c|c|c|}
\hline Reference & Flow type & Approach \\
\hline Van der Ham and Winterwerp (2001) & $\begin{array}{l}\text { Tidal channel in the } \\
\text { Ems/Dollard estuary }\end{array}$ & $\begin{array}{l}\text { Tidal pressure is computed using time-varying } \\
\text { depth-averaged flow velocity }\end{array}$ \\
\hline Makinson (2002) & Antartica & Forcing with $M_{2}$ and $\sin \left(\omega_{M_{2}} t-\phi\right)$ forcing \\
\hline Ralston and Stacey (2006) & Channel of San Francisco bay & $\begin{array}{l}\text { The forcing is calculated by matching model } \\
\text { output to a given SSH and velocity time series } \\
\text { as describe by Burchard (1999) }\end{array}$ \\
\hline Umlauf et al (2007) & Estuarine dynamics & $\begin{array}{l}\text { GOTM scenarios, } H=15 \mathrm{~m} \text {, forcing with only } \\
M_{2}=44714 \mathrm{~s} \text { which prescribes sinusoidal time } \\
\text { series for the vertically averaged momentum in } \\
\text { west-east direction }\end{array}$ \\
\hline Umlauf et al (2007) & Annual North Sea Simulation & $\begin{array}{l}\text { GOTM scenarios, } 59^{\circ} 20^{\prime} N, 1^{\circ} 17^{\prime} \text {, forcing } \\
\text { with only } M_{2}=44714 s \text { forcing with } \partial_{x} \zeta \text { and } \\
\partial_{y} \zeta \text { construct with tide extrapolated from ob- } \\
\text { servation during autumn } 1998\end{array}$ \\
\hline Smaoui et al (2007) & English Channel & $\begin{array}{l}\text { Tidal pressure gradient computed with a } 2 \mathrm{D} \\
\text { vertically integrated tidal model. }\end{array}$ \\
\hline Jones and Monismith (2008) & $\begin{array}{l}\text { Shallow estuarine in Suisun } \\
\text { bay }\end{array}$ & $\begin{array}{l}\text { The tidal pressure gradient is computed using } \\
\text { the method describe by Burchard (1999) }\end{array}$ \\
\hline Present & Iroise sea & $\begin{array}{l}\text { The tide pressure }-g \nabla_{H} \zeta \text { is computed by finite } \\
\text { differences with SSH using CST France from } \\
\text { SHOM with } 115 \text { main harmonics constituents } \\
\text { (Le Roy and Simon, 2003) with } \Delta x=1000 \mathrm{~m}\end{array}$ \\
\hline
\end{tabular}

Table 2 1D vertical water-column study including tidal forcing with mean and turbulent quantities as un-

known computational variables 
The boundary condition at the surface was set as:

$$
v_{T} \frac{\partial \mathbf{U}}{\partial z}(z=H)=\frac{\tau_{S}}{\rho_{0}}
$$

where $\tau_{S}=\rho_{A i r} C d_{S} U_{10} \mathbf{U}_{10}$ is the surface stress components, $\rho_{A i r}=1.25 \mathrm{~kg} . \mathrm{m}^{-3}$ is the air density, $C d_{S}=0.016$ is the surface drag coefficient, $\mathbf{U}_{\mathbf{1 0}}$ is the wind at $10 \mathrm{~m}$ above the surface. Meteorological forcing was taken from the ARPEGE analysis of Méteo France. The ARPEGE analysis has a spatial resolution of $0.5^{\circ}$ in longitude and latitude and provides four analysed fields per day.

The bottom boundary condition set as:

$$
v_{T} \frac{\partial \mathbf{U}}{\partial z}(z=0)=\frac{\tau_{B}}{\rho_{0}}
$$

where $\tau_{B}=\rho_{0} C d_{B} U(z=\delta) \mathbf{U}(\mathbf{z}=\delta)$ are the bottom stresses consistent with the tide model of Le Roy and Simon (2003), $C d_{B}=\frac{\kappa^{2}}{\ln \left(\frac{z+\delta+z_{B}}{z_{B}}\right)}, \delta$ is a position above the bottom surface defined by the size of the first differential element, $\kappa=0.4$ is the Von Karman constant, $z_{B}=3.5 \mathrm{~mm}$ is the bed roughness as used by (Muller et al, 2007) in the Iroise sea and by Duhaut (2009) for the validation of their turbulence scheme.

Only a few authors considered the impact of the Hasselmann force (eq. 3) in the 1D mixed layer (table 3) and none included the effects of earth rotation, density stratification and tidal oscillations at the same time.

\subsubsection{Forcing of mean momentum by the Stokes drift through the Hasselmann force}

We used the WW3 model to obtain wave properties at point A. Details of numerical implementation and configuration of WW3 can be found in Ardhuin et al (2009). Using the full directional wave energy spectra $E(\mathbf{q}, \theta)$ given by WW3 we can express the Stokes drift vector for deep water waves (Kenyon, 1969) as:

$$
U_{\text {Stokes }}(z)=4 \pi \int_{0}^{2 \pi} \int_{0}^{\infty} \mathbf{u}_{\theta} q f e^{2 q z} E(q, \theta) d q d \theta
$$




\begin{tabular}{|c|c|c|c||}
\hline \hline Reference & Rotation & Stratification & Tide \\
\hline \hline Groeneweg and Klopman (1998) & no & no & no \\
\hline Rascle et al (2006) & yes & no & no \\
Rascle (2007) & yes & yes & no \\
\hline Rascle and Ardhuin (2009) & yes & yes & yes \\
\hline present & yes \\
\hline \hline
\end{tabular}

Table 3 1D vertical modelling including the Hasselmann force (term 2 of r.h.s. in eq. 2) with presence or not of rotation (term 1 of r.h.s. in eq.2), stratification (eq. 8) and tide (term 4 of r.h.s. in eq. 2)

where $q(f)^{2}$ is the magnitude of the wave number $\mathbf{q}$. Thanks to linear waves theory in deep water, we obtain the relation between the wave number and the frequency which can be written as:

$$
q=\frac{(2 \pi f)^{2}}{g}
$$

where $g$ is the acceleration of gravity.

Stokes drift is needed to compute the Hasselmann force. The Hasselmann force is also known as the Stokes-Coriolis. Stokes drift will only affect the equation for mean velocity and not the one for temperature due to the assumption of horizontal homogeneity

\subsubsection{Equation for mean temperature T}

With the same assumption for the momentum equation, starting from the thermodynamics part of primitive equation, we got an equation for temperature $T$ :

$$
\frac{\partial T}{\partial t}=-\frac{\partial}{\partial z} \overline{\mathbf{w} \theta}+\Phi_{T}
$$

${ }^{2}$ We use $\mathbf{q}$ as notation for the wave vector magnitude and not the conventional $\mathbf{k}$ because $k$ denotes the turbulent kinetic energy. 
where $\theta$ is the turbulent random temperature fluctuation and $\Phi_{T}$ is the radiative atmospheric flux computed by Luyten and De Mulder (1992). The surface boundary condition for temperature is

$$
v_{T} \frac{\partial T}{\partial z}(z=H)=\frac{Q_{T}}{\rho_{0} C_{p}}
$$

where $Q_{T}$ is the turbulent heat flux at the air-sea interface, $C_{p}=3986 \mathrm{~J} . \mathrm{kg} .{ }^{\circ} \mathrm{C}^{-1}$ is the heat capacity.

We did not impose a heat flux at the bottom:

$$
v_{T} \frac{\partial T}{\partial z}(z=0)=0
$$

Currents and temperature were coupled indirectly through turbulent viscosity $v_{T}$ and diffusivity $\kappa_{T}$ obtained from the turbulent kinetic energy $k$.

3.2 Turbulence model for small scale mixing

Because it was successfully used for modelling the Iroise sea (Muller et al, 2007; Muller, 2008; Muller et al, 2009) we use the model of Gaspar et al (1990). The particularity of this model is that turbulent length scales are obtained by an integral equation.

\subsubsection{Definition of turbulent length scales}

One weak point of classical equation turbulence closure models is the specification of a turbulent length scale and the fact that most models set all process length scales proportional to a single length (Mellor and Yamada, 1982). Bougeault and Lacarrere (1989) proposed two lengths, one is $l_{\varepsilon}$ for the dissipation and the other is the mixing length $l_{k}$. which are

$$
l_{k}=\min \left(l_{u}, l_{d}\right)
$$


and

$$
l_{\varepsilon}=\sqrt{\left(l_{u} l_{d}\right)}
$$

Constitutive length scales $l_{u}$ and $l_{d}$ are related to the upward $\left(l_{u}\right)$ or downward $\left(l_{d}\right)$ movement of a fluid particle to convert all of its original TKE into turbulent potential energy. We computed $l_{u}$ and $l_{d}$ by integrals equations $13 \mathrm{a}$ and $13 \mathrm{~b}$ :

$$
\begin{aligned}
& \frac{g}{\rho_{0}} \int_{z}^{z+l_{u}}\left[\bar{\rho}(z)-\bar{\rho}\left(z^{\prime}\right)\right] d z^{\prime}=k(z) \\
& \frac{g}{\rho_{0}} \int_{z}^{z-l_{d}}\left[\bar{\rho}(z)-\bar{\rho}\left(z^{\prime}\right)\right] d z^{\prime}=k(z)
\end{aligned}
$$

We recall that in a stably stratified water column with a constant density gradient this straightly yield $l_{u}=l_{d}$ and $l_{d}=\sqrt{2} l_{b}$ where $l_{b}=\frac{1}{\sqrt{k} N}$ is the buoyancy length scale and $N$ is the Brunt-Wäisäilä frequency. The two length scales $l_{k}$ and $l_{\varepsilon}$ appear in the turbulent kinetic equation and without stratification, we recovered classical triangular profile (fig. 6). Thanks to the integration, possible trajectories of turbulent particules, modelled by constitutive length scales $l_{u}$ and $l_{d}$, are limited by the action of buoyancy force (related to $l_{b}$ ) or by boundary conditions. As recalled by Bougeault and Lacarrere (1989) and Gaspar et al (1990) with this formulation, the acceptable values of $z+l_{u}$ and $z-l_{d}$ are naturally limited by the ocean surface and bottom.

The length scales $l_{d}$ and $l_{u}$ are not directly related to wind wave activity but to stratification. Because the sea surface temperature is related to breaking waves as shown by Mellor and Blumberg (2004) with the Craig and Banner (1994) model, these length scales are indirectly affected by sea surface waves.

\subsection{Turbulent kinetic energy (TKE) equation}

Using the eddy diffusivity concept, turbulent kinetic energy dissipation parametrization (Kolmogorov, 1942) and assuming that diffusivity $v_{T}$ for $U$ and $k$ are the same, we got 
the TKE equation

$$
\frac{\partial k}{\partial t}=\frac{\partial}{\partial z} v_{T} \frac{\partial k}{\partial z}+v_{T} \frac{\partial \mathbf{U}}{\partial z} \frac{\partial \mathbf{U}}{\partial z}-\kappa_{T} \frac{\partial T}{\partial z}-C_{\varepsilon} \frac{k^{3 / 2}}{l_{\varepsilon}}
$$

in which $C_{\varepsilon}$ (table 4) is empirical constant. In eq. 14, the term on the left hand side (1.h.s.) is the time rate of change of the turbulent kinetic energy, the first term on the right hand side (r.h.s.) represents vertical diffusion, the second term represents energy generation by velocity shear, the third term is the destruction of turbulence by stratification, and the final term is the dissipation of turbulent kinetic energy.

The eddy diffusivities were related to the TKE according to:

$$
v_{T}=C_{k} l_{k} k^{1 / 2}
$$

where $C_{k}$ (table 4 ) is a parameter and $l_{k}$ is a mixing length related to energetic structures. The turbulent vertical flux that appears in eq. 2 was parameterized using the classical concept of eddy diffusivity:

$$
-\overline{\mathbf{u} w}=v_{T} \frac{\partial U}{\partial z}
$$

Taking a turbulent Prandtl number as unit (Mellor and Yamada, 1982; Gregg et al, 1985; Peters et al, 1988) with the concept of eddy diffusivity, we got $\kappa_{T}=v_{T}$ and the turbulent thermal vertical flux that appears in eq. 8 is expressed as:

$$
-\overline{\mathbf{w} \theta}=v_{T} \frac{\partial T}{\partial z}
$$

At the sea bed, we assumed zero flux of turbulent energy:

$$
v_{T} \frac{\partial k}{\partial z}=0
$$

The surface boundary condition for waves breaking following Craig (1996) is written as:

$$
v_{T} \frac{\partial k}{\partial z}=\alpha u_{*}^{3}
$$

where $u_{*}=\sqrt{\frac{\tau_{S}}{\rho_{0}}}$ is the friction velocity and $\alpha$ is the sea surface waves energy factor. For simulation without wave enhancement, $\alpha$ was set to zero: 


$$
\begin{array}{|l|l|l|}
\hline C_{\varepsilon}=0.7 & C_{k}=0.1 & C_{\mu}=0.09 \\
\hline
\end{array}
$$

Table 4 Set of constants used to model turbulence

3.4 Sea surface waves breaking (whitecapping) with the wave energy factor

Physically, breaking waves is a highly 3D process and the depth of its vertical penetration is proportional to the wave-number of the wave that dissipates (?). As recalled by ? the dominance of breaking sea surface waves is a source of turbulence at a below-surface depth of 0.04 to 0.2 times the wavelength of the dominant breaking waves. ? found that relative depth increases with increasing values of $U_{10} / c_{d}$, where $c_{d}$ is the phase speed of the dominant waves.

Using a 3D ocean model, ? showed that including sea surface waves in the vertical eddy viscosity had a significant influence on surface currents, particularly in deep water. ? parameterized total viscosity by the sum of the meteorological term, the current dependent term and the waves term. The waves term was taken as $0.028 H s^{2} / T_{m}$ where $T_{m}$ was a characteristic period of the waves field computed with the wave model WAM.

Adding a waves term is important for generalisation and to avoid fitting some constants. ? found that including a wave-dependent Charnock parameter eliminated the need to find an optimised constant value and provided acceptable surge prediction across the eastern Irish Sea for different surge events.

In a 1D model, Craig and Banner (1994) parameterized the overall transfer of waves to turbulence by breaking waves with a single parameter $\alpha=100$. Using $\alpha$ is a common parametrization for an unstratified (Craig, 1996; Stacey and Pond, 1997; Burchard, 2001b; Rascle et al, 2006; Sun et al, 2008) and stratified (Kundu, 1980; d'Alessio et al, 1998; Noh, 1996; Noh and Kim, 1999; Kantha and Clayson, 2004; Stips et al, 2005; Jones and Monismith, 2008; Rascle and Ardhuin, 2009) 1D mixed layer. Jones and Monismith (2008) 
and Rascle and Ardhuin (2009) added a more realistic feature by incorporating a surface roughness length scale proportional to the significant wave height $H_{S}$. In agreement with the result of ? that found that with empirical estimates, the roughness length was of the same order as $H s$

The Gaspar et al (1990) turbulence model does not include surface roughness length but several studies have been successfully conducted using this turbulence model (Muller et al, 2007, 2009; Lazure et al, 2009; Muller et al, 2010). For this reason, in our first approach, we chose to not include surface roughness length scale in our model. We incorporated a realistic feature through a time dependent wave energy factor. Following Craig and Banner (1994) with the scaling of Terray et al (1996a) we parameterized $\alpha$ as:

$$
\alpha=\frac{\bar{c}}{u_{*}}
$$

where $\bar{c}$ is an integral measure of the characteristic velocity associated with the energy flux. We built $\bar{c}$ as:

$$
\bar{c}=\frac{g \bar{T}}{2 \pi}
$$

where $\bar{T}$ is the mean period over all wave spectra given by WW3 defined by:

$$
\bar{T}=\left[\frac{\int_{0}^{\infty} \int_{0}^{2 \pi} f^{2} E(f, \theta) d \theta d f}{\int_{0}^{\infty} E(f) d f}\right]^{-1 / 2}
$$

We can see that $\bar{c}$ is built as phase velocity and not as group velocity, and it is better to see $\bar{c}$ as the group velocity with a ratio 2 . Parameterizing wave breaking is a very complex process: some parts of the waves spectra contribute more than others to wave breaking. 


\section{Numerical simulation and results}

We performed six different runs as summarized in table 5. The particularity of $1 \mathrm{D}$ modelling was detailed in the previous section and more detail about the 3D configuration and implementation can be found in Lazure et al (2009). We used both uniform and near surface refined vertical grids. The uniform simulations were computed using 200 levels (1D, 1D-B, $1 \mathrm{DS}, 1 \mathrm{D}-\mathrm{BS}$ in the table 5) and the refined simulations were computed using 30 levels (1D $\sigma$ and $3 D \sigma$ in the table 5). The vertical discretization for $1 D \sigma$ and $3 D \sigma$ are exactly the same.

\begin{tabular}{||l|c|c|c|c||}
\hline \hline Symbol & Breaking waves & Stokes drift & Grid & Dim. \\
\hline \hline $1 \mathrm{D}$ & $\alpha$ & $U_{\text {Stokes }}$ & $d z$ & \\
\hline $1 \mathrm{D} \sigma$ & no & no & constant & $1 \mathrm{D}$ \\
\hline 3D $\sigma$ & no & no & sigma & $1 \mathrm{D}$ \\
\hline $1 \mathrm{D}-\mathrm{B}$ & yes & no & constant & $1 \mathrm{D}$ \\
\hline $1 \mathrm{D}-\mathrm{S}$ & no & yes & constant & 1D \\
\hline 1D-BS & yes & yes & constant & 1D \\
\hline \hline
\end{tabular}

Table 5 Symbols for runs described in the present paper. Effects included are waves breaking (letter B) and Stokes drift (letter S). The Stokes drift was included as defined in section 3.1.2 with formula 6. The whitecaps TKE flux was parameterized as described in section 3.4 with eq. 20. The letter $\sigma$ refers to runs with sigma coordinates as defined in Lazure and Dumas (2008) with 30 levels. Runs without sigma coordinates were run with 200 constant vertical elements. 1D stands for a one-dimensional simulation and 3D for a threedimensional simulation.

4.1 Overestimation of inertial motion in $1 \mathrm{D}$ vertical assumption

We compared numerical results from simulation with MARS in 1D and 3D with results of H.F. radar (fig. 5). The sampling interval was imposed by the post-processed H.F. radar 
data as 3 hours. And we limited the study to phenomena occurring in a period longer than 9.6 hours (2.5 cpd for spectrums fig. 3, fig. 4 and fig. 5, for changes in energy distribution fig. 7) or 8 hours (3 cpd for time-frequency analysis fig. 8).

One major problem with $1 \mathrm{D}$ vertical simulation is overestimation of kinetic energy due to near-inertial frequencies (Pollard and Millard Jr, 1970; Mellor, 2001). The spectral density of kinetic energy was overestimated by a factor 40 at the inertial frequency of $-1.5 \mathrm{cpd}$ (fig. 5). The diurnal tide was overestimated by a factor 3 . The frequency at $-1.5 c p d$ was overestimated because in the 1D model near inertial waves (IGWs) could not be generated to radiate in the $3 \mathrm{D}$ space. Point $\mathrm{A}$ is a location where IGWs are generated. At this location, IGWs transmit energy to other regions where they can break, reflext or be converted.

For the clockwise $M_{2}(-1.93 c p d)$ frequency, the 1D model overestimated the spectral density of the radar by $33 \%$ and the $3 \mathrm{D}$ model by $2 \%$. For the counter-clockwise $M_{2}$ $(1.93 \mathrm{cpd})$ frequency the tendancy was inversed, the 1D model underestimated the spectral density of the radar by $-8 \%$ and the $3 \mathrm{D}$ model by $-17 \%$ (see fig. 5). From a statistical point of view, the difference between spectral density of radar and models was within the confidence interval (left box in fig. 5) so we can argue that the spectra matched at -1.93 cpd and $1.93 \mathrm{cpd}$. The 1D model considerably overestimated radar measurements at the frequencies -1 cpd and -1.5 cpd (inertial frequency) and both models underestimated the spectral density between 0 cpd and $1.7 c p d$.

In the low frequency part of the spectrum, between $]-0.8,0.8[\mathrm{cpd}$ the H.F. radar spectrum was quasi-symmetrical. Numerical models (1D or 3D) did not display these quasisymmetries and underestimated the positive frequency between $] 0,1.7[c p d$.

The frequency between $]-1.7,1.7[$ at point $\mathrm{A}$ was dominated by a near-inertial frequency around $-1.5 \mathrm{cpd}$. This is not the case everywhere in the Iroise sea, and closer to the coast at point B (fig. 4), where the whole water column is well mixed, the diurnal density of 


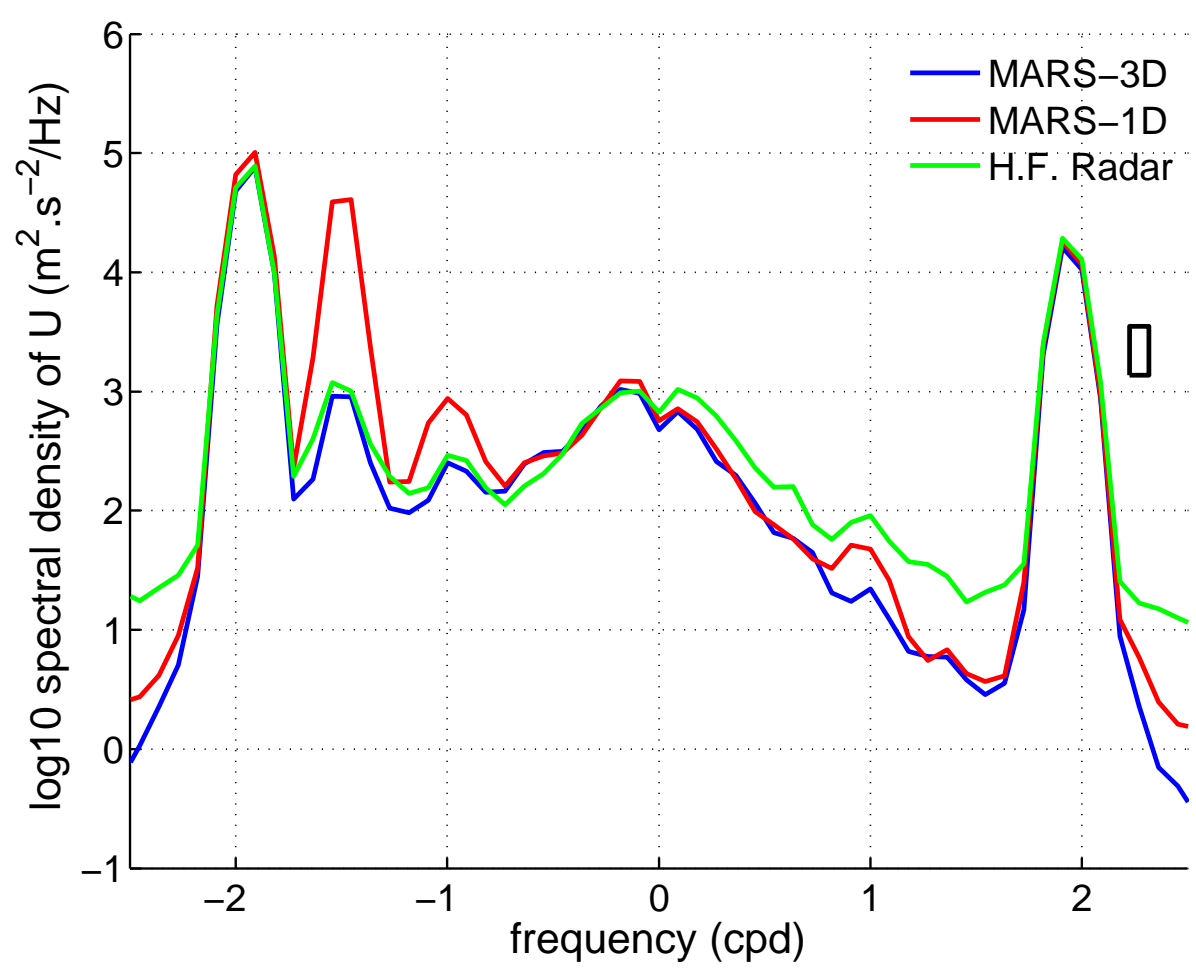

Fig. 5 Rotary power spectra of the quasi-Eulerian current from MARS-1D (red), MARS-3D (blue) and H.F. radar (green) at point A (fig. 1). The spectra were estimated using half-overlapping segments of 264 hour long over the parts of the time series with no gaps. The number of samples taken was 45 given an equivalent degrees of freedom of 138 at a spectral resolution of 0.09 (horizontal size of the rectangle). At the $95 \%$ confidence level, the relative error was is linked to the vertical size of the rectangle. Negative frequencies are clockwise (Coriolis like) polarized motions and positive frequencies are counter-clockwise polarized motions.

spectral energy at tidal frequency was larger than the density of spectral energy at inertial frequency.

\subsection{The barrier effect of the thermocline}

The thermocline acts as a barrier to inertial movement and the near-inertial movement above the thermocline has the same intensity. The position of the thermocline was at a depth of 
around $33 m$ (fig. 8) which is consistent with observations of thermal stratifications in the Iroise sea (Le Boyer et al, 2009).

\subsubsection{Time-Frequency analysis}

Because in this section we focus on near inertial motion, we performed a tidal analysis using the R_T_TIDE code (Leffler and Jay, 2009), a modified version of T_TIDE (Pawlowicz et al, 2002) which uses a more robust method for harmonic fitting. We applied detiding to each velocity component to obtain the residual current. This analysis on the full time series allowed the removal of the deterministic semi-diurnal constituents $\left(M_{2}, S_{2}, N_{2}, K_{2}\right)$ and diurnal constituents $\left(K_{1}, O_{1}, P_{1}, Q_{1}\right)$ with periods defined in table 1 .

Rotary time-frequency analysis gave the temporal localization of an oscillating event with an indication of its circular polarization. Fig. 8 is a continuous time-frequency diagram using the wavelet method (Liu and Miller, 1996). Fig. 7 shows monthly variations in spectral energy. By defining the partitioned velocity $\mathbf{U}_{\left[f_{\text {low }}, f_{\text {high }}[\right.}$ on the bandwidths $\left[f_{\text {low }}, f_{\text {high }}[\right.$ by

$$
\mathbf{U}_{\left[f_{\text {low }}, f_{\text {high }}[\right.}=\int_{f_{\text {low }}}^{f_{\text {high }}} \mathbf{A}(f) e^{i 2 \pi f} d f
$$

where $\mathbf{A}(f)$ is the spectral amplitude of $\mathbf{U}^{3}$ and computing a partitioned velocity for each month, we were able to monitor the monthly energy at three bandwidths (fig. 7). Tables 6 , 7 and 8 show a comparison of dates where stratification (table 6), destratification (table 7) and deepening of the mixed layer (tab. 8) occured.

In the offshore Iroise sea, the water column is unstratified for only three months (February, March and April) (fig. 7). Stratification generally settles around April (table 6). Destratification (table 7), which ends around December, is more complex and is linked to deepening of the mixed layer. A one-month period of deepening (table 8 ) of the mixed layer preceded

\footnotetext{
3 We use equivalently $\mathbf{U}$ as a vector or $\mathbf{U}$ as a complex number: $\mathbf{U}=(u, v)$ or $\mathbf{U}=u+\imath v$
} 
the destratification process (table 7). During the stratified period, the residual current was dominated by near-inertial frequencies around $-1.5 \mathrm{cpd}$ (fig. 8; fig. 7). The near-inertial energy reached maximum after stratification settled and before the beginning of the destratification process, and exhibited a relative minimum around the month of September (fig.

7).

\begin{tabular}{|l||c|c|c|c|c|c|c|}
\hline & wavelet $30 m>10^{-2}$ & wavelet $50 m>10^{-2}$ & iso- $T 12^{\circ}$ & $T>16^{\circ}$ & $\mathbf{U}_{[1.3,1.7[}$ & $\kappa_{T}$ & $\frac{1}{2} q^{2}$ \\
\hline 2005 & $05 / 03$ & $27 / 10$ & $08 / 04$ & $13 / 06$ & 06 & $23 / 03$ & $23 / 03$ \\
2006 & $12 / 04$ & $02 / 11$ & $02 / 05$ & $07 / 06$ & 06 & $31 / 03$ & $16 / 04$ \\
2007 & $03 / 04$ & $06 / 11$ & $08 / 04$ & $09 / 06$ & 05 & $08 / 04$ & $08 / 04$ \\
2008 & $01 / 06$ & & $15 / 04$ & $25 / 05$ & & $29 / 03$ & $15 / 04$ \\
\hline
\end{tabular}

Table 6 Dates of stratification processes identified from the time-frequency diagram at $-30 \mathrm{~m}$ fig. 8 when wavelet energy was $>10^{-2}$ (column 2 at $30 \mathrm{~m}$ and column 3 at $50 \mathrm{~m}$, below the surface), variations in temperature fig. 8 with iso-temperature $12^{\circ} \mathrm{C}$ (column 3) and when temperatures were above $16^{\circ} \mathrm{C}$ (column 4), variations in partitioned velocity fig. 7 when near-inertial velocity dominated, variations in turbulent diffusivity fig. 6 when $\kappa_{T}$ was close to zero (column 8), variations in TKE fig. 9 when TKE was close to zero (column 9).

\begin{tabular}{|c||c|c|c|c|c|}
\hline & wavelet $<10^{-2}$ & $T<16^{\circ}$ & iso- $T 12^{\circ}$ & $\mathbf{U}_{[1.3,1.7]}$ & $\kappa_{T}$ and $\frac{1}{2} q^{2}$ \\
\hline 2006 & $18 / 01$ & $21 / 11 / 2005$ & $08 / 01 / 2006$ & $11 / 2005$ & $08 / 01$ \\
2007 & $28 / 01$ & $29 / 11 / 2006$ & $31 / 12 / 2006$ & $12 / 2006$ & $16 / 01$ \\
2008 & $09 / 01$ & $07 / 12 / 2007$ & $08 / 01 / 2008$ & $10 / 2007$ & $24 / 01$ \\
\hline
\end{tabular}

Table 7 Dates of destratification processes identified from the time-frequency diagram in fig. 8 when wavelet energy was $>10^{-2}$ (column 2), variations in temperature fig. 8 when temperatures were above $16^{\circ} \mathrm{C}$ (column 3) and with an iso-temperature of $12^{\circ} \mathrm{C}$ (column 4), variations in partitioned velocity fig. 7 when near-inertial velocity dominated (column 5), variations in turbulent diffusivity fig. 6 and TKE fig. 9 when TKE was close to zero (column 6). 


\begin{tabular}{|c||c|c|}
\hline & $\kappa_{T}$ & $\frac{1}{2} q^{2}$ \\
\hline 2006 & $21 / 11$ & $17 / 10$ \\
2007 & $29 / 11$ & $09 / 10$ \\
2008 & $23 / 12$ & $21 / 11$ \\
\hline
\end{tabular}

Table 8 Date of deepening of the ocean mixed layer identified from variations in turbulent diffusivity fig. 6 when $\kappa_{T}$ was close to zero (column 2), variations in TKE fig. 9 when TKE was close to zero (column 3).

\subsubsection{Vertical dependencies}

The same pattern of inertial frequency was found at $-30 \mathrm{~m}$ and $-50 \mathrm{~m}$ when the mixed layer penetrated above $50 \mathrm{~m}$ (fig. 8). There inertial peak had the same value at $-0.29 \mathrm{~m}$, $-0.89 m,-30.29 m$ (fig. 10). The dynamics above the thermocline reacted homogeneously to the inertial frequency in 1D. This had to be confirmed in 3D because other phenomena like near IGWs radiation can change the dynamics. At $-90 m$ the inertial peak was negligible because it was far from the thermocline and at $50 \mathrm{~m}$ it was $10 \%$ of the surface value because of the deepening of the mixed layer (fig. 10).

Unlike the current, there was no signature of inertial frequency in the TKE spectrum fig. 11. Close to the surface, the TKE energy spectrum reached maximum at $0.19 \operatorname{cpd}(T \approx 5$ days) and subsequently decayed until $2 \mathrm{cpd}$. Far from the surface, the TKE energy spectrum exhibited an energy peak at a the same frequency of $M_{2}$. Far from the surface the energy at $2 c p d$ was still high but less than at the frequency of $M_{2}$. The resolution in frequency was greater than the difference in frequency between $S_{2}(2.000 c p d)$ and $K_{2}(2.005 c p d)$. For the mean current, the amplitude of $S_{2}$ was approximately 4 times greater than $K_{2}$ but no tidal analysis was performed on TKE. 

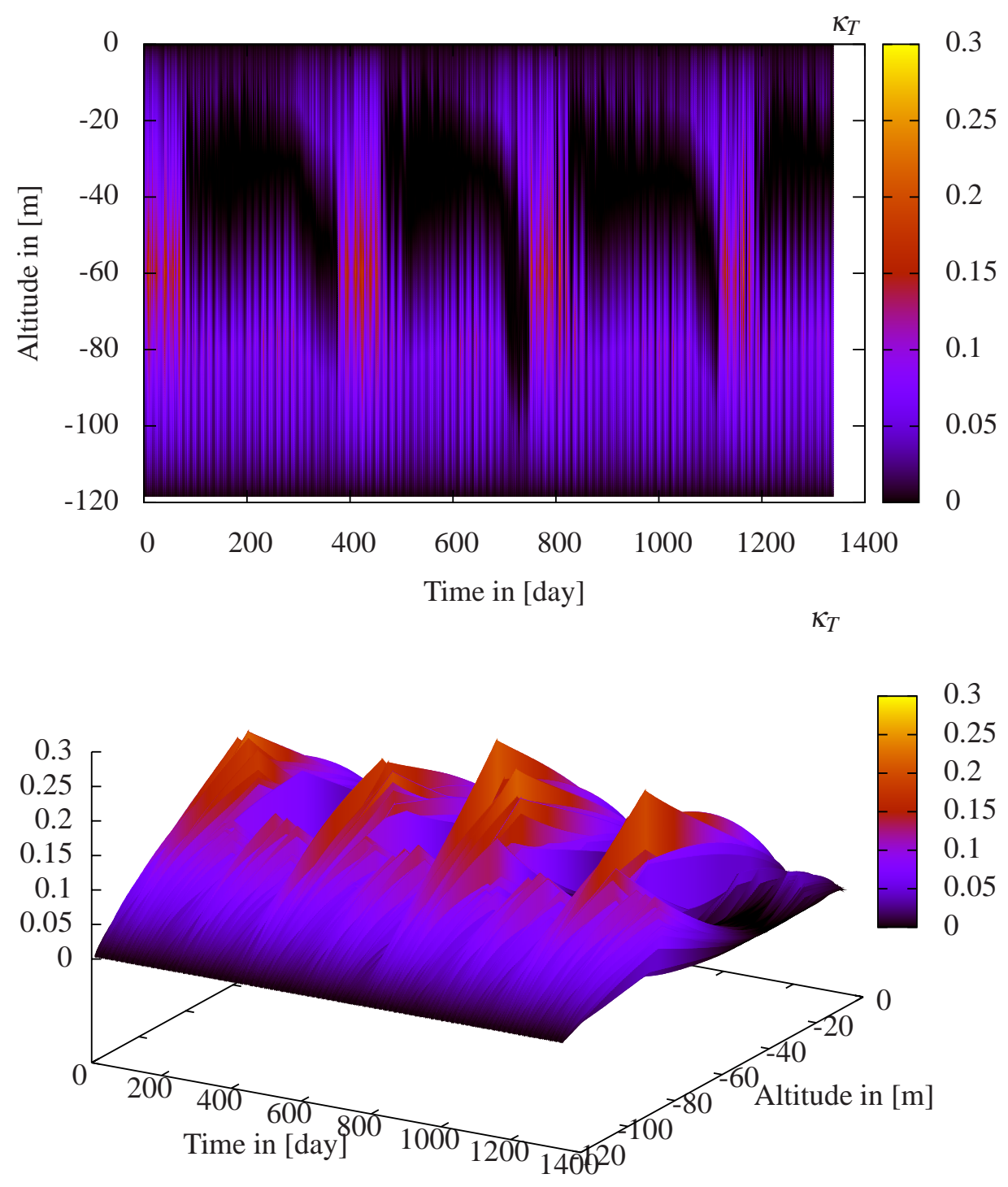

Fig. 6 Variations in turbulent diffusivity $\kappa_{T}\left(m \cdot s^{-2}\right)$ at point A (defined in fig. 1). from January 1, 2005 to September 1,2008 . The top panel is a $(t, z)$ map with a clear view of the instationarity of $\kappa_{T}$. The bottom panel is a $\left(t, z, \kappa_{T}\right)$ surface with a direct view of the vertical dependencies of $\kappa_{T}$.

4.3 The influence of sea surface waves

\subsubsection{Comparison with H.F. radar}

Considering the global performance on all the bandwidths ] $-2.5,2.5$ [, we found the correlation coefficient between H.F. radar and MARS-1D to be around $\approx 0.6$ (fig. 12,top). Because 


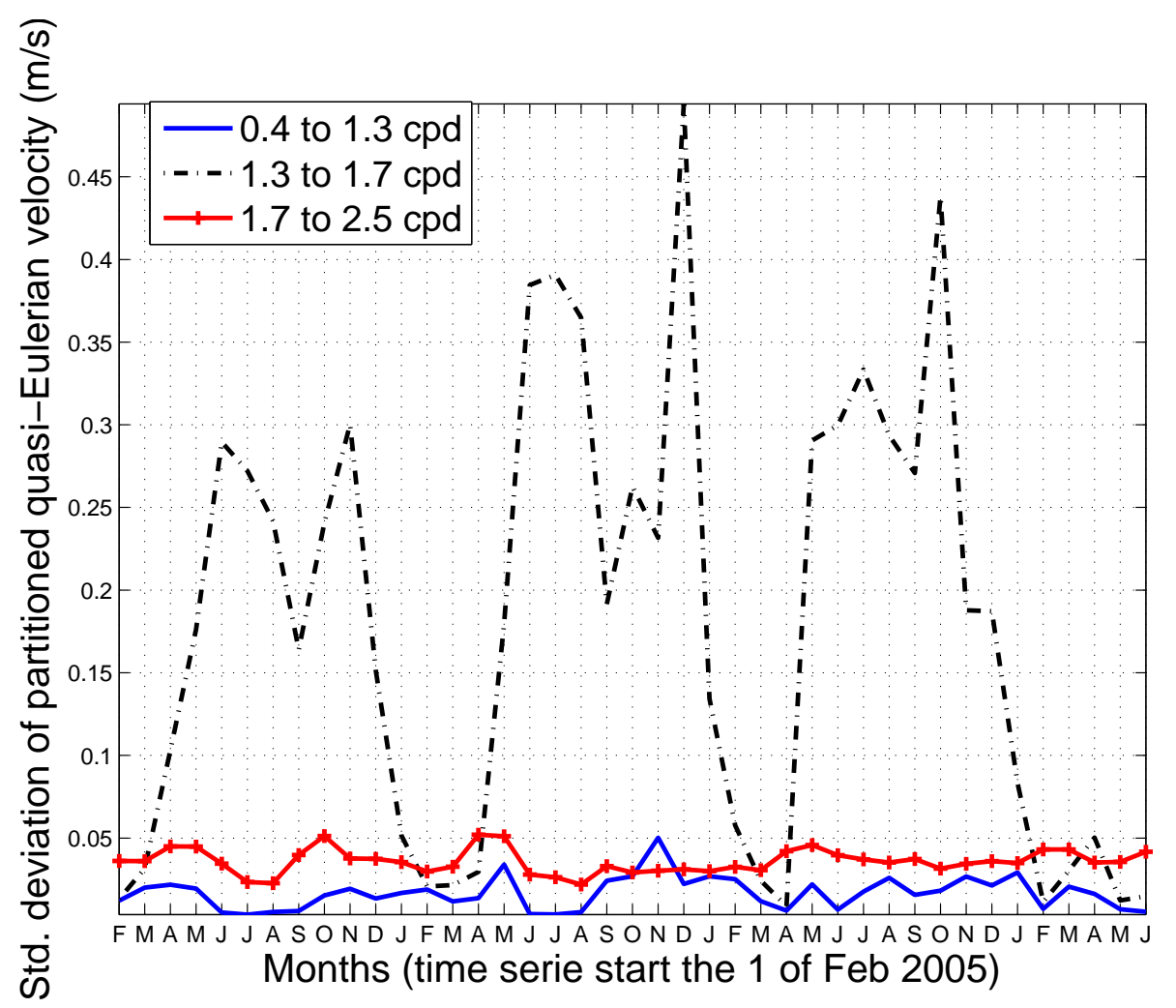

Fig. 7 Variations in the monthly velocity partition at point A (fig. 1) obtained by averaging power spectra at different bandwidths, between February 2005 and June 2008.

of the overestimation of the inertial frequency, the normalized standard deviation was of $\approx 1.45$ indicating more variability in the model than in the H.F. radar (fig. 12, top). Due to the fact that we considered that the overall bandwidth ] $-2.5,2.5[$, the differences between parametrization were small. But even if the differences were small, sea state parameterization increased model accuracy (fig. 12, bottom). Generally, using whitecap parameterization reduced the normalized standard deviation and using Stokes drift increased the correlation coefficient but this increase was small and needed to be confirmed in 3D simulation.

Adding sea state parameterization affected the mean turbulent kinetic energy (MKE) and the TKE equilibrium. Taking Stokes drift and waves breaking into account modified the 

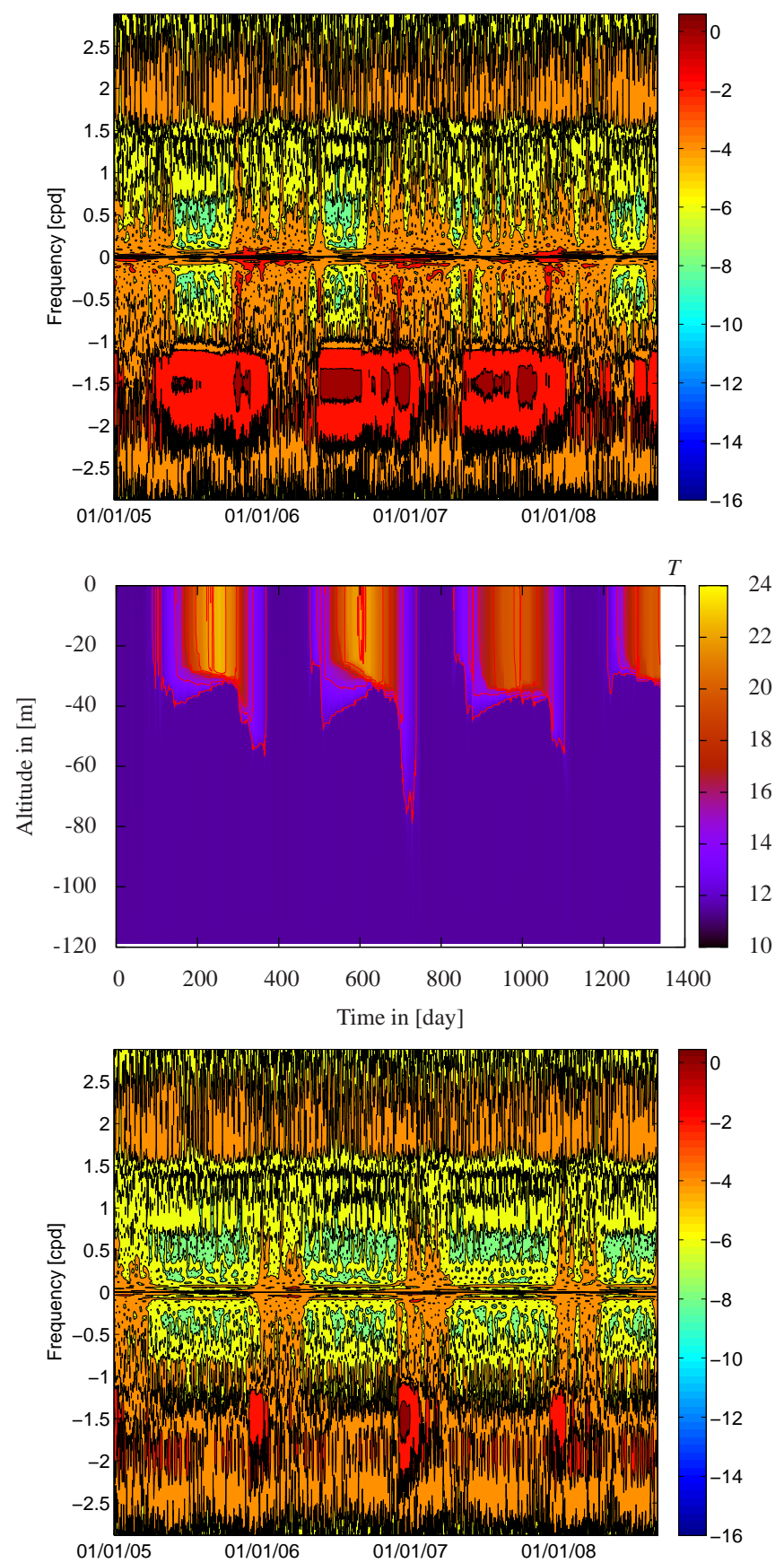

Fig. 8 Time-frequency diagram according to the wavelet method (Liu and Miller, 1996) of the detided quasi-

Eulerian current normalized power wavelet density and temperature evolution $(t, z, T)$ in ${ }^{\circ} \mathrm{C}$ (middle panel) from January 1, 2005 to Deptember 1, 2008 computed with MARS-1D at point A (fig. 1). Currents taken from the time-frequency diagram were located at $30 \mathrm{~m}$ (top figure) and at $50 \mathrm{~m}$ (bottom panel). DOG wavelets were used as the mother function. Negative frequencies are clockwise (Coriolis like) polarized motions and positive frequencies are counter-clockwise polarized motions. 


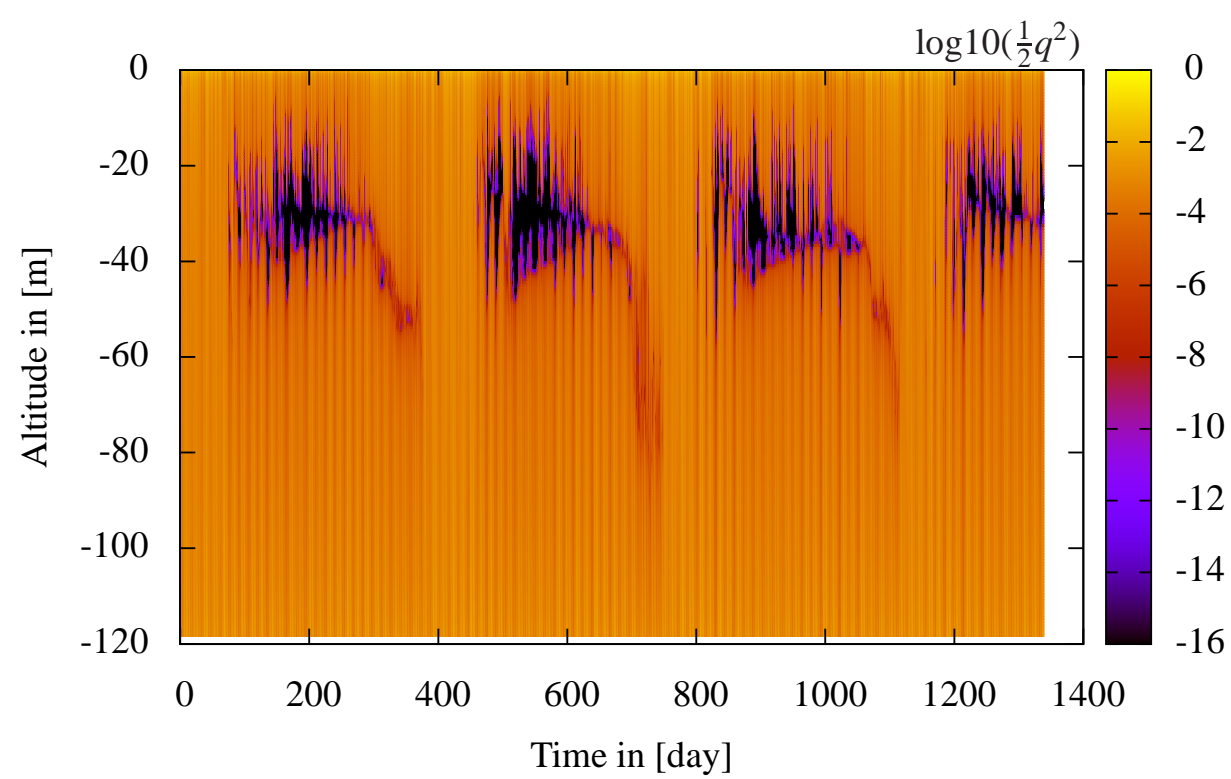

Fig. $9 \log 10$ variations in turbulent kinetic energy density $\left(t, z, \log 10\left(\frac{1}{2} q^{2}\right)\right.$ from January 1,2005 to September 1, 2008 at point A (fig. 1).

MKE at all frequencies between tidal and inertial peaks (fig. 13). Including Stokes drift in the model increased the MKE. The TKE input due to waves breaking decreased the MKE (fig. 13).

Taking Stokes drift into account increased coherency throughout the bandwidth ] 2.5, 2.5[, except for tidal peaks where Stokes drift had no effect. Disregarding bandwidth ] $0.5,0.8[$ and ] 1, 1.6[ the parameterization of whitecaps increased coherency (fig. 14,top; table 9).

We found that Stokes drift reduced the phase lag of $17^{\circ}$ at a frequency of $-0.6 \mathrm{cpd}$ and of $40^{\circ}$ at a frequency of $1.6 \mathrm{cpd}$ (fig. 14,bottom). Globally, the minimum phase lag was obtained for the model with Stokes drift and whitecap parameterization. 


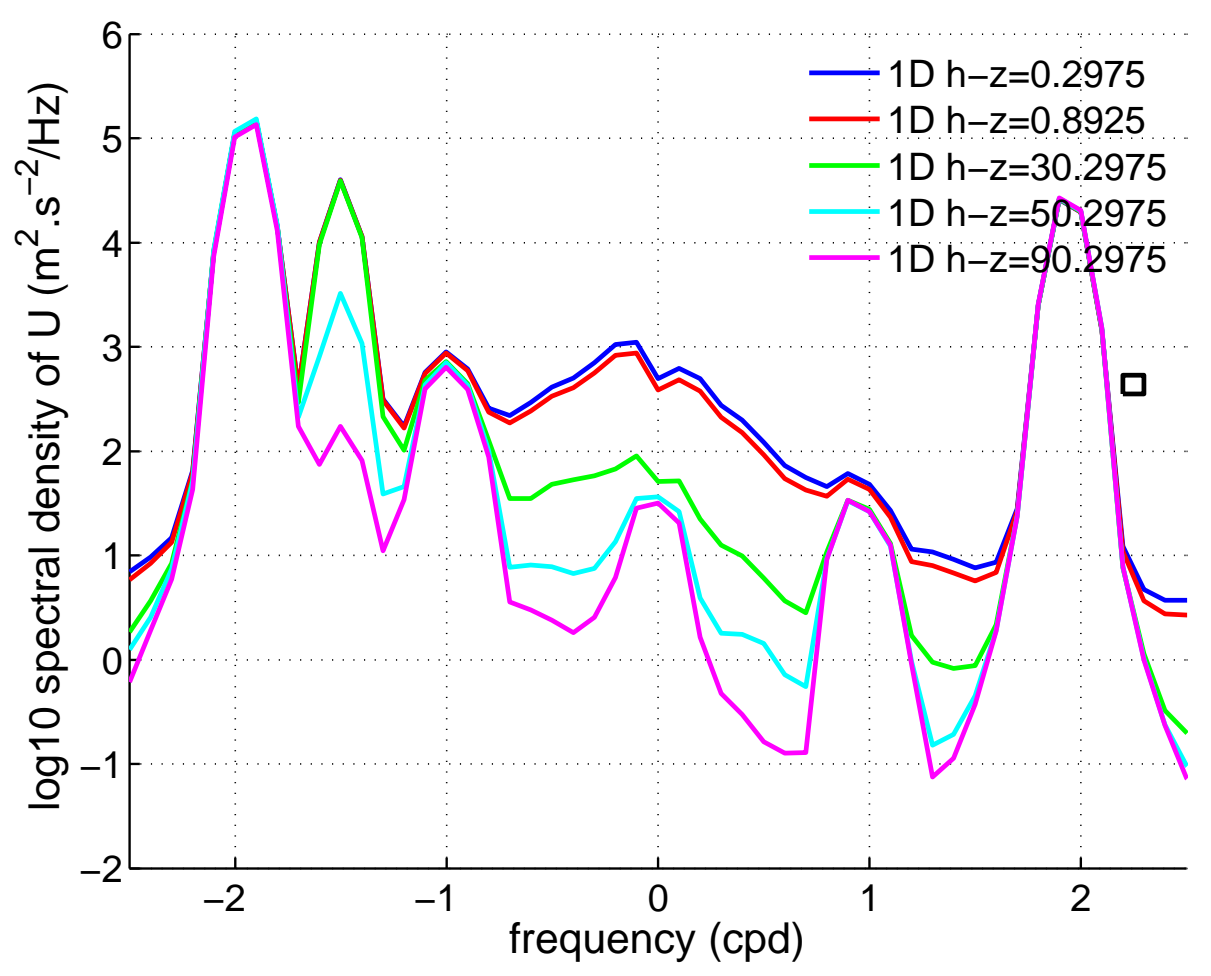

Fig. 10 Rotary spectra of quasi-Eulerian current obtainted with MARS-1D at different depths at point A (fig.

1). The spectra were estimated using half-overlapping segments 264 hour long. The number of samples taken was 265 and the equivalent degrees of freedom was 709 for a spectral resolution of 0.09 cpd (horizontal size of the rectangle). At the $95 \%$ confidence level, the relative error was linked to the vertical size of the rectangle. Negative frequencies are clockwise (Coriolis like) polarized motions and positive frequencies are counter-clockwise polarized motions.

\subsubsection{Sensitivity of the stratified layer}

The stratified layer depth (SLD) was estimated by scanning the ocean column starting from the surface. If the TKE decreased and was greater than $k_{c}=210^{-5} \mathrm{~m}^{2} \cdot \mathrm{s}^{-2}$ the position was used to obtain the SLD time series. As a diagnosis, the probability density function (PDF) of the SLD is plotted in fig. 15 with estimated kernel density (Botev et al, 2010). In summer, when stratification was active, the SLD was is equal to the mixed layer depth (MLD). In 


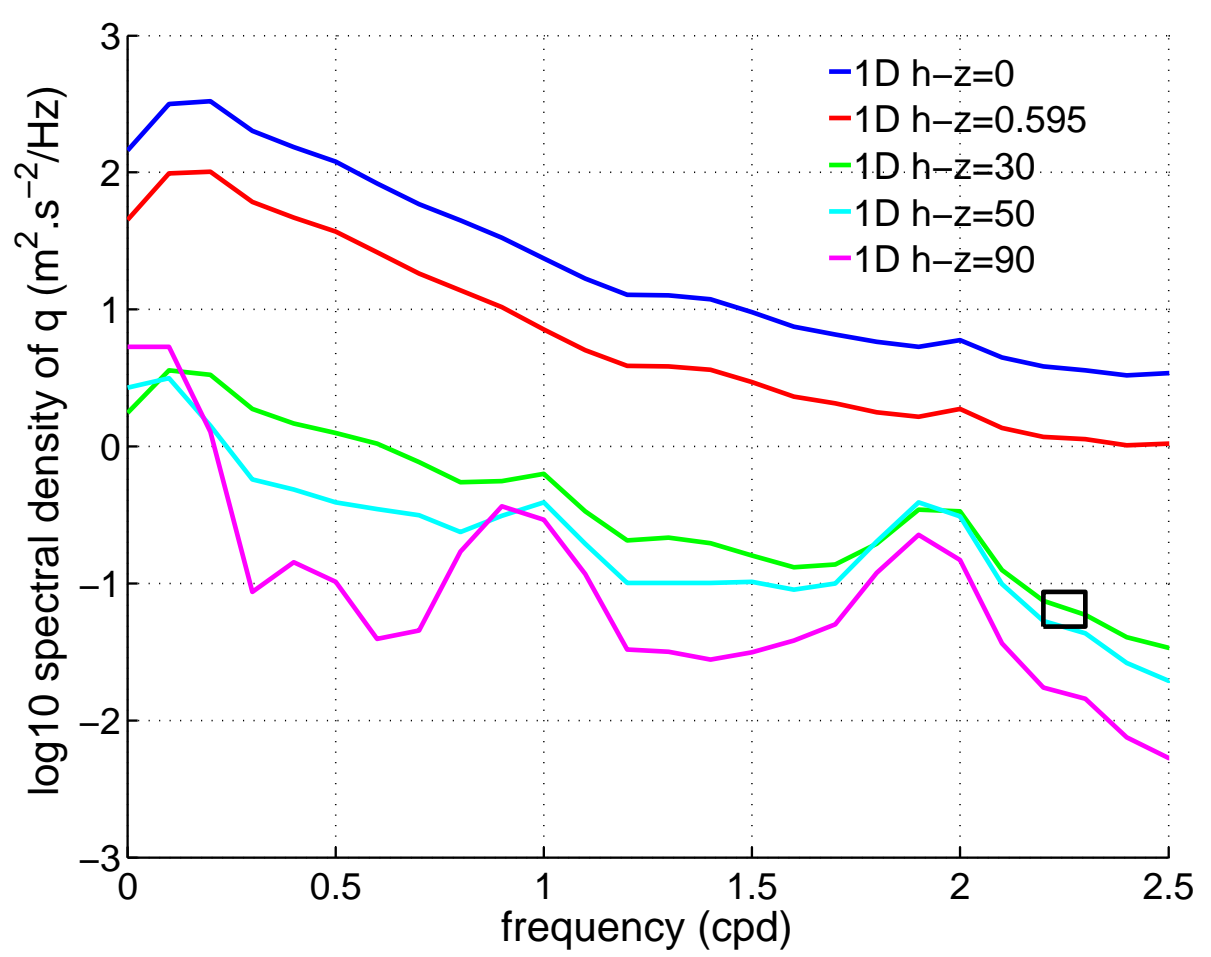

Fig. 11 TKE spectra obtained with MARS-1D at different depths at point A (fig. 1). The spectra were estimated using half-overlapping segments of 264 hour long. The number of samples taken was 265 and the equivalent degrees of freedom were 354 for a spectral resolution of $0.09 \mathrm{cpd}$ (horizontal size of the rectangle). At the $95 \%$ confidence level, the relative error was linked to the vertical size of the rectangle.

winter when there was no stratification, the SLD was positioned at the surface. Converesly, in winter, the MLD was positioned at the bottom because the whole water column was well mixed. Fig. 9 shows variations in TKE. In fig. 9 at a fixed time in a stratified period, the SLD corresponds to the distance between the surface and the top of the black zone ( $\approx$ zero TKE). The PDF of SLD (fig. 15) had three lobes, one at $22.2 \mathrm{~m}$, the second at $31 \mathrm{~m}$ and the third at $46 \mathrm{~m}$. The third lobe was sensitive to sea surface waves breaking parameterization and increased by $3.7 \mathrm{~m}$ due to TKE input at the surface. 


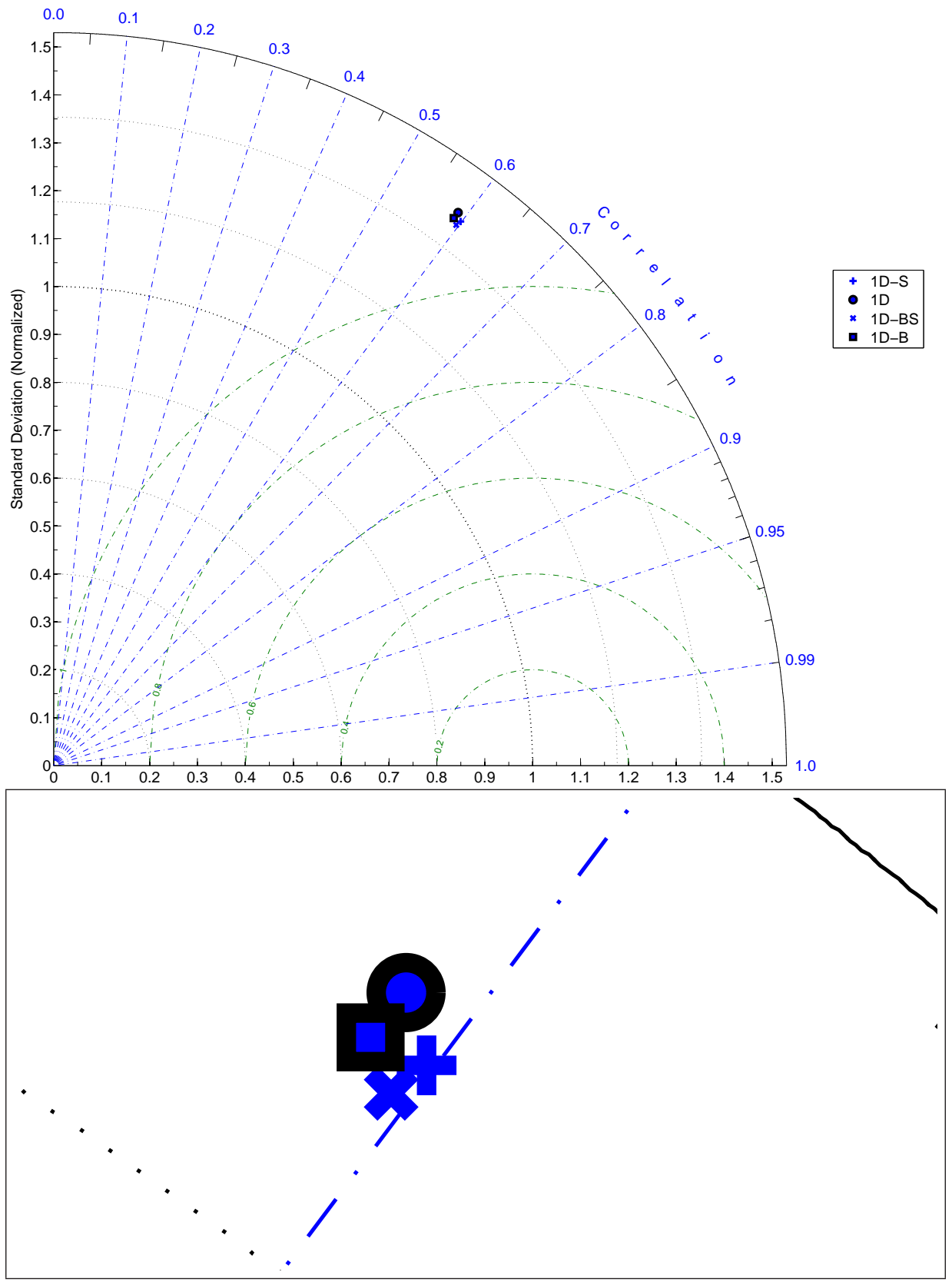

Fig. 12 Taylor diagram (Taylor, 2001) between quasi-Eulerian current from MARS-1D runs and H.F. radar measurement at point A (fig. 1). For denoising, the quasi-Eulerian current was filtered using the Fourier method. The frequencies in bandwidth $[-2.5,2.5]$ were kept. The radius is the normalized standard deviation defined by $\sigma_{u^{M A R S 1 D}} / \sigma_{u^{R a d a r}}$. The angle is the corre-

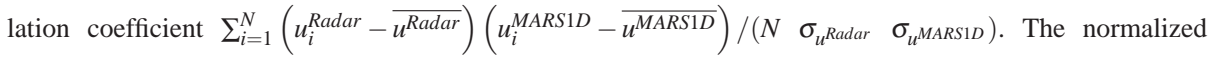
root mean square difference is the distance to point 1 on the horizontal axis and is defined by $\sqrt{\sum_{i=1}^{N}\left(u_{i}^{\text {Radar }}-u_{i}^{\text {MARS } 1 D}\right)^{2}} /\left(N \sigma_{u^{\text {Radar }}}\right)$. 


\begin{tabular}{|c|c|c|c|c|c|}
\hline Bandwidth & Rating & 1D & 1D-B & 1D-S & 1D-BS \\
\hline$]-2.5,-2.2[$ & \begin{tabular}{l|l}
1 & \\
2 & \\
3 & \\
4 &
\end{tabular} & $\times$ & $x$ & $x$ & $x$ \\
\hline$]-1.46,-1.30[$ & $\begin{array}{l}1 \\
2 \\
3 \\
4\end{array}$ & $\times$ & $x$ & $x$ & $x$ \\
\hline$]-0.9,0.5[$ & $\begin{array}{l}1 \\
2 \\
3 \\
4\end{array}$ & $x$ & $x$ & $x$ & $\times$ \\
\hline$] 0.5,0.8[$ & $\begin{array}{l}1 \\
2 \\
3 \\
4\end{array}$ & $x$ & $x$ & $x$ & $\times$ \\
\hline ]1,1.6[ & $\begin{array}{l}1 \\
2 \\
3 \\
4\end{array}$ & $x$ & $x$ & $x$ & 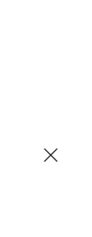 \\
\hline$] 1.9,2.5[$ & $\begin{array}{l}1 \\
2 \\
3 \\
4\end{array}$ & $x$ & $x$ & $x$ & $\times$ \\
\hline
\end{tabular}

Table 9 Performance of coherency spectra based on fig. 14. Symbols 1D, 1D-B, 1D-S, 1D-BS represent different runs with increasing complexity of sea surface waves parameterization and are defined in table 5 . The frequency bandwidth is defined as cycles per day $(c p d)$. A rating of 1 is the best coherency and a rating of 4 is the worst coherency 


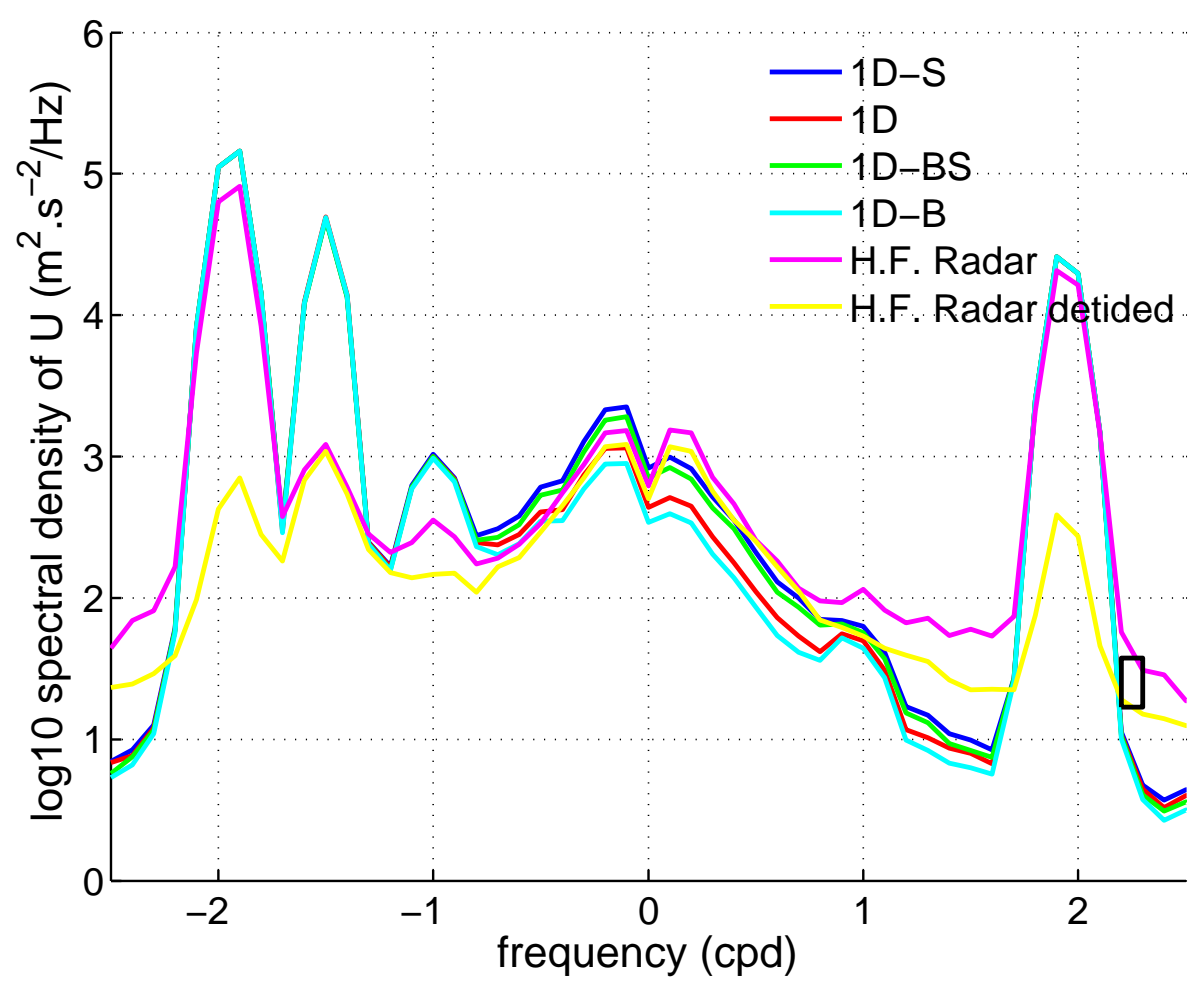

Fig. 13 Rotary spectra of a quasi-Eulerian current obtained with MARS-1D for different sea states parameterization and the quasi-Eulerian current measured by H.F. radar at point A (fig. 1). The spectra were estimated using half-overlapping segments of 264 hour long over the parts of the time series with no gaps. The number of degrees of freedom used was 192 at a spectral resolution of 0.09 cpd (horizontal size of the rectangle). At the $95 \%$ confidence level, the relative error was linked to the vertical size of the rectangle. Negative frequencies are clockwise (Coriolis like) polarized motions and positive frequencies are counter-clockwise polarized motions. 

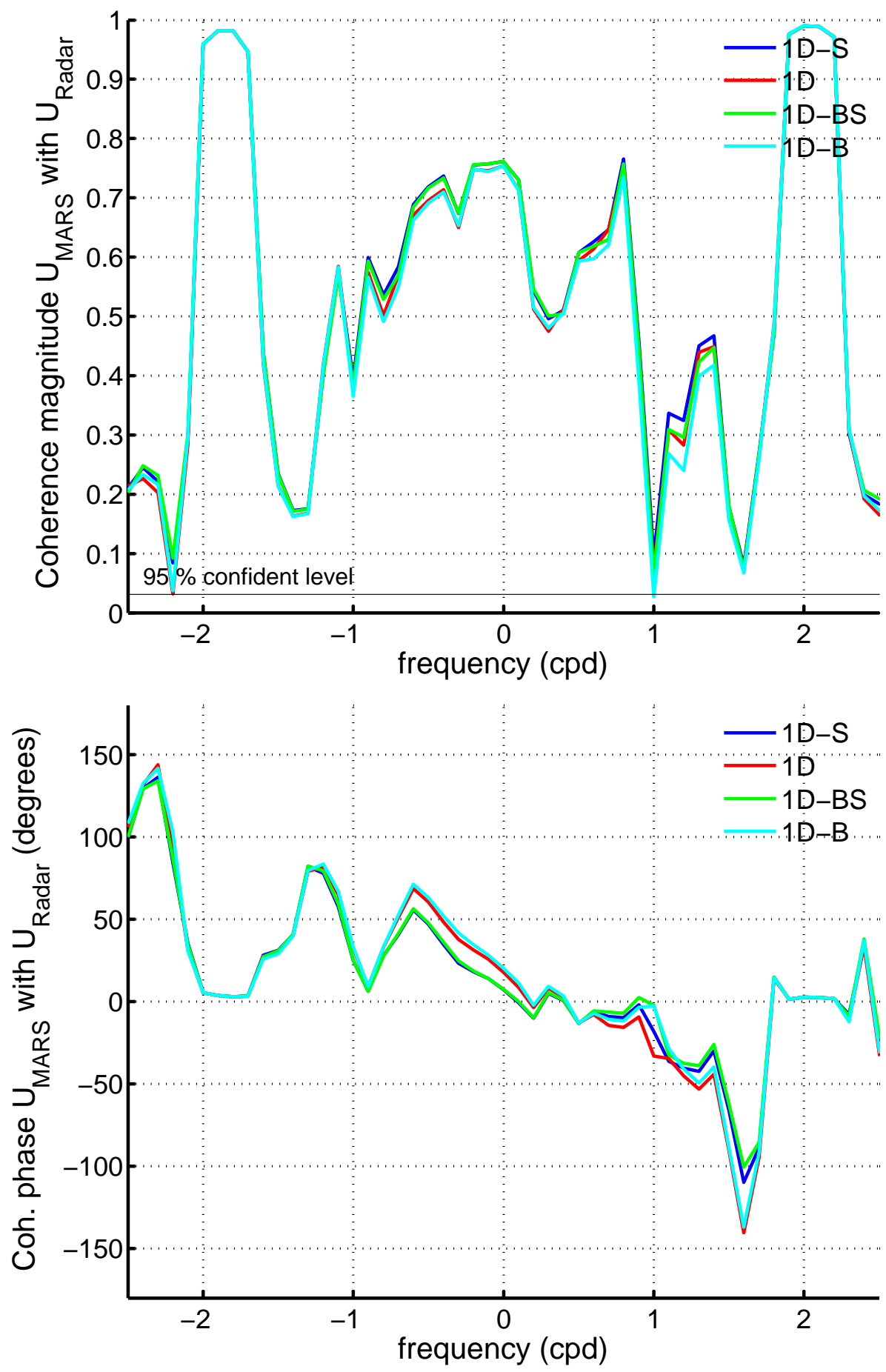

Fig. 14 Rotary co-spectra of the quasi-Eulerian current computed with MARS-1D and the current measured by H.F. radar at point A (fig. 1). The top panel shows the magnitude commonly called coherency spectra and bottom panel shows the phase. The number of degrees of freedom was 192 at a spectral resolution of $0.09 \mathrm{cpd}$. Coherence is significant at the $95 \%$ confidence level for a value of 0.025 . Negative frequencies are clockwise (Coriolis like) polarized motions and positive frequencies are counter-clockwise polarized motions. 


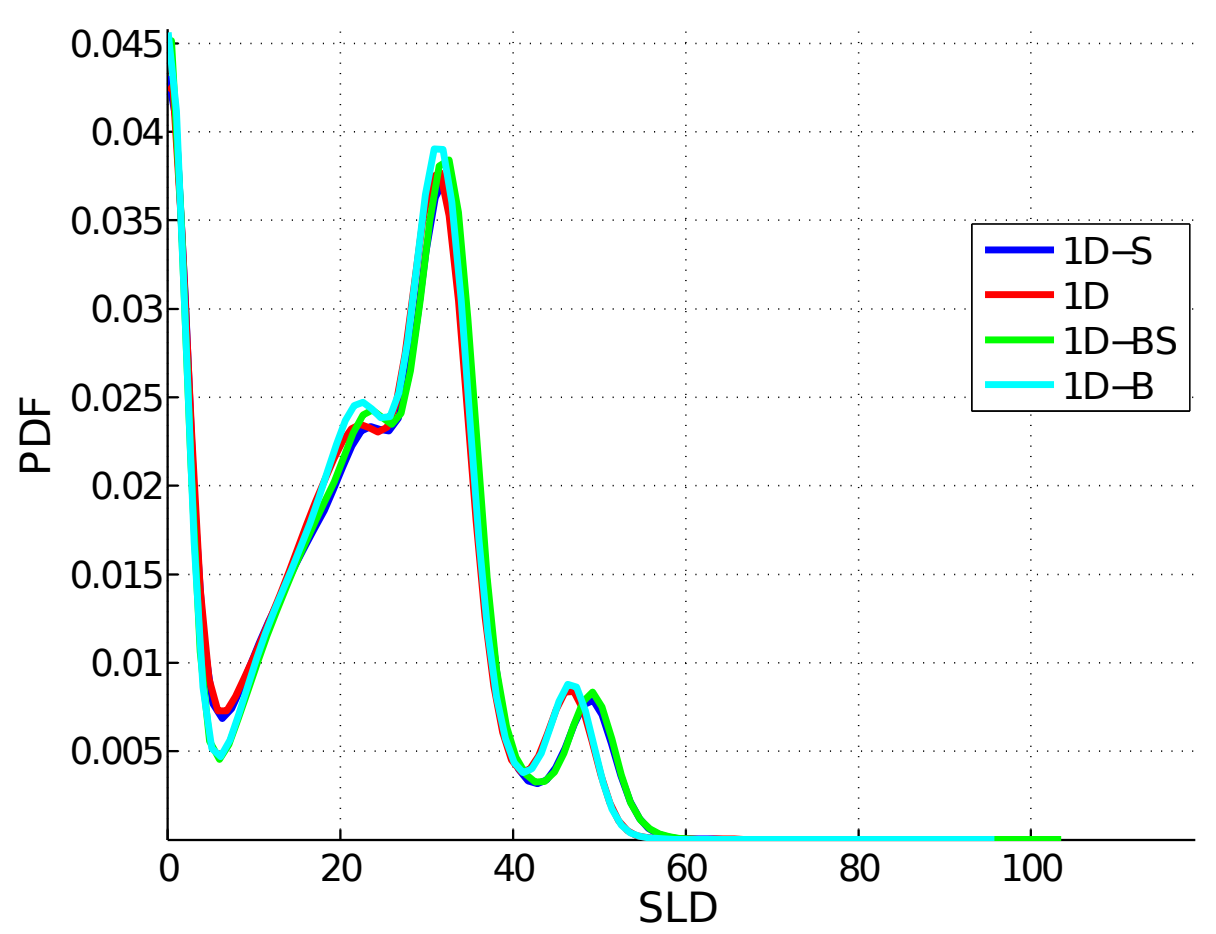

Fig. 15 Probability density functions of the stratified layer depth for each sea surface waves parameterization at point A (fig. 1). 


\section{Discussion, conclusion and future work}

We have demonstrated here that using Stokes drift of sea surface waves in the context of a generalized Lagrangian mean smally increases the numerical accuracy of 1D vertical mixed layer simulation with realistic forcing. Due to the error caused by $1 \mathrm{D}$ approximation on the near inertial frequency and because we observed that this error did not occur in the 3D simulation, we would expect better results when this sea surface waves parameterization is incorporated in 3D ocean code.

Both the Hasselmann force and the injection of TKE due to breaking waves are important. The Hasselmann force is more energetic at low frequencies because this force has its origin in low-pressure atmospheric systems that generate sea surface waves. The Hasselmann force increases the mean kinetic energy (MKE) at low frequencies and the injection of TKE tends to decrease MKE. There is a competitive effect between the Hasselmann force and injection of TKE which is why it is necessary to include both effects consistently. We also observed that sea surface waves parameterization can affect the water column at a depth of $50 \mathrm{~m}$ through a destratification process by increasing the depth of the mixing layer. Similar results were obtained by Mellor and Blumberg (2004).

In comparison with radar, there was some kind of broken symmetry at low frequencies at $]-0.7 ; 0.7[c p d$ in the model spectra. This is not due to the dimensionality of the problem because spectra obtained with a 3D simulation also have anti-symmetric energy distribution at this bandwidth. The dissymmetry persisted deeper in the water-column. Finding where this discrepancy originates could significantly increase oceanic current forecasting.

In the future we need to tackle the remaining problems (Burchard, 2001a) concerning the roughness length scale and incorporate in our model a modified Bougeault and Lacarrere (1989) length scale. It would be interesting to examine near-surface dissipation rate 
measurements by comparing them with observations (Anis and Moum, 1995; Drennan et al, 1996; Terray et al, 1996b) but perhaps new observations of dissipation rate specific to the Iroise sea would be needed. Because saving the complete sea surface waves spectra requires a lot of data storage, it would be useful to build parameterization of Stokes drift based on principal sea state parameters $\left(H s, f_{p}, \bar{T} \ldots\right)$. We also need more realistic parameterization of the wave energy factor of turbulence breaking based on sea waves and meteorological parameters.

Acknowledgements We thank Fabrice Ardhuin for his comments and helpful suggestions about wave modelling and data processing. We thank Guillaume Charria for discussion and advice on statistical and wavelet analysis. We thank Louis Marié, Héloise Muller and Nicolas Rascle for discussion on rotary analysis and Iroise sea mechanisms. We thank the anonymous reviewer who helped us significantly improve our paper. G.S. acknowledges the PREVICOT project for providing a grant. Sea state data were provided by the IOWAGA team.

\section{References}

Altazin-Pichon A (1981) Application d'un modèle de thermocline à la formation du front thermique en mer d'iroise. confrontation des résultats avec des mesures in situ. Thèse de doctorat spécialité océanographie physique, Université de Bretagne Occidentale, Brest

Andrews DG, McIntyre ME (1978) An exact theory of nonlinear waves on a Lagrangianmean flow. Journal of Fluid Mechanics 89:609-646

Anis A, Moum JN (1995) Surface wave-turbulence interactions: Scaling $\varepsilon(z)$ near the sea surface. J Phys Meteor 25:2025-2045

Ardhuin F, Jenkins AD, Belibassakis Ka (2008a) Comments on The Three-Dimensional Current and Surface Wave Equations. Journal of Physical Oceanography 38(6):1340 
Ardhuin F, Rascle N, Belibassakis KA (2008b) Explicit wave-averaged primitive equations using a generalized Lagrangian mean. Ocean Modelling 20(1):35-60

Ardhuin F, Marie L, Rascle N, Forget P, Roland A (2009) Observation and estimation of Lagrangian, Stokes and Eulerian currents induced by wind and waves at the sea surface. J Phys Oceanogr 39:2820-2838

Birrien JL (1987) Cycles de variations des éléments nutritifs et du phytoplancton en baie de Douardenez et dans les secteurs adjacents: importance du front côtier de l'Iroise. PhD thesis, Université de Bretagne Occidentale, Brest, France

Botev ZI, Grotowski JF, Kroese DP (2010) Kernel density estimation via diffusion. Annals of Statistics 38(5)

Bougeault P, Lacarrere P (1989) Parameterization of Orography-Induced Turbulence in a Mesobeta-Scale Model. Monthly Weather Review 117(8):1872-1890

Burchard H (1999) Recalculation of surface slopes as forcing for numerical water column models of tidal flow. Applied Mathematical Modelling 23(10):737-755

Burchard H (2001a) Applied turbulence modelling in marine waters, habilitation thesis, Institute for Oceanography, University of Hamburg, Germany

Burchard H (2001b) Simulating the wave-enhanced layer under breaking surface waves with two-equation turbulence models. J Phys Oceanogr 31:3133-3145

Cambon G (2008) Etude numérique de la mer d'Iroise: dynamique, variabilité du front d'Ouessant et évaluation des échanges cross-frontaux. $\mathrm{PhD}$ thesis, Université de Bretagne Occidentale

Cochin V (2006) Evaluation of ground wave HF/VHF radars for operational oceanography. $\mathrm{PhD}$ thesis, Ph. D. Thesis, National School of Telecommunications of Brittany, France Craig PD (1996) Velocity profiles and surface roughness under breaking waves. Journal of Geophysical Research-Oceans 101(C1) 
Craig PD, Banner ML (1994) Modeling wave-enhanced turbulence in the ocean surface layer. Journal of physical oceanography 24(12):2546-2559

d'Alessio SJD, Abdella K, McFarlane NA (1998) A new second-order turbulence closure scheme for modeling the oceanic mixed layer. J Phys Oceanogr 28:1624-1641

Davies AM, Hall P, Howarth MJ, Knight P, Player R (2001) A detailed comparison of measured and modeled wind-driven currents in the North Channel of the Irish Sea. Journal of Geophysical Research 106(C9):19,683-19,713

Drennan WM, Donelan AA, Terray EA, Katsaros KB (1996) Oceanic turbulence dissipation rate measurements in SWADE. J Phys Oceanogr 26:808-815

Duhaut T (2009) Notes sur les schémas de turbulence à deux équations. Tech. rep., IFREMER DYNECO-PHYSED, Pointe du Diable, 29280 Plouzané, France

Ekman V (1905) On the influence of the earths rotation on ocean currents. Ark. f. Mat Ast och Fysik, Stockholm 6(2):11

Emery W, Thomson R (2001) Data analysis methods in physical oceanography. Elsevier Science Ltd

Gaspar P, Grégoris Y, Lefevre J (1990) A simple eddy kinetic energy model for simulations of the oceanic vertical mixing: Tests at Station Papa and long-term upper ocean study site. Journal of Geophysical Research 95(C9)

Gonella J (1972) A rotary-component method for analysing meteorological and oceanographic vector time series. Deep-Sea Res 19(12):833-846

Gregg MC, Peters H, Wesson JC, Oakey NS, Shay TJ (1985) Intensive measurements of turbulence and shear in the equatorial undercurrent. Nature 318(6042):140-144

Groeneweg J (1999) Wave-current interactions in a generalized lagrangian mean formulation. Ph.d. thesis, Delft University of Technology, The Netherlands 
Groeneweg J, Klopman G (1998) Changes of the mean velocity profiles in the combined wavecurrent motion described in a GLM formulation. Journal of Fluid Mechanics 370:271-296

Van der Ham R, Winterwerp J (2001) Turbulent exchange of fine sediments in a tidal channel in the Ems/Dollard estuary. Part II. Analysis with a 1DV numerical model. Continental Shelf Research 21(15):1629-1647

Hasselmann K (1970) Wave-driven inertial oscillations. Geophysical \& Astrophysical Fluid Dynamics 1(3):463-502

Jones NL, Monismith SG (2008) Modeling the influence of wave-enhanced turbulence in a shallow tide-and wind-driven water column. Journal of Geophysical Research 113

Kantha LH, Clayson AC (2004) On the effect of surface gravity waves on mixing in the oceanic mixed layer. Ocean Modelling 6(2):101-124

Kenyon KE (1969) Stokes drift for random gravity waves. J Geophys Res 74(28):6991-6994

Kolmogorov A (1942) Equations of turbulent flow of an incompressible fluid. Izv AN SSSR, ser fiz 6(1-2):56-58

Kundu PK (1980) A numerical investigation of mixed-layer dynamics. Journal of Physical Oceanography 10(2):220-236

Lazure P, Dumas F (2008) An external-internal mode coupling for a 3D hydrodynamical model for applications at regional scale (MARS). Advances in water resources 31(2):233250

Lazure P, Garnier V, Dumas F, Herry C, Chifflet M (2009) Development of a hydrodynamic model of the Bay of Biscay. Validation of hydrology. Continental Shelf Research 29(8):985-997

Le Boyer A, Cambon G, Daniault N, Herbette S, Le Cann B, Marie L, Morin P (2009) Observations of the Ushant tidal front in September 2007. Continental Shelf Research 
29(8):1026-1037

Le Corre P, Mariette V (1985) Le Front Thermique d'Ouessant et Août et Septembre 1982. Campagne SATIR-DYNATLANT IFREMER, Campagnes Océanographiques Françaises 1

Le Duff M, Hily C (1999) Environnement naturel de lIroise. Bilan des connaissances et intérêt patrimonial MATE/UBO, Brest 1:78

Le Fevre J, Grall J (1970) On the relationships of Noctiluca swarming off the western coast of Brittany with hydrological features and plankton characteristics of the environment. Journal of Experimental Marine Biology and Ecology 4(3):287-306

Le Roy R, Simon B (2003) Réalisation et validation dun modèle de marée en Manche et dans le Golfe de Gascogne Application à la realisation dun nouveau programme de réduction des sondages bathymétriques. Rapport détudes SHOM 2(03)

Leffler K, Jay D (2009) Enhancing tidal harmonic analysis: Robust (hybrid L1/L2) solutions. Continental Shelf Research 29(1):78-88

Lewis J, Shulman I, Blumberg A (1998) Assimilation of Doppler radar current data into numerical ocean models. Continental shelf research 18(5):541-559

Liu PC, Miller GS (1996) Wavelet transforms and ocean current data analysis. Journal of Atmospheric and Oceanic Technology 13(5):1090-1100

Luyten P, De Mulder T (1992) A module representing surface fluxes of momentum and heat. Tech. rep., Technical Report No 9 - MAST-0050-C

Makinson K (2002) Modeling tidal current profiles and vertical mixing beneath FilchnerRonne Ice Shelf, Antarctica. Journal of Physical Oceanography 32:202-215

Mariette V (1983) Effets des échanges atmosphériques sur la structure thermique marine; application à des zones du large et à une zone côtière. $\mathrm{PhD}$ thesis, Thèse de Doctorat, Université de Bretagne Occidentale 
Mariette V, Le Cann B (1985) Simulation of the formation of Ushant thermal front. Continental Shelf Research 4(6):637-660

Mariette V, Rougier G, Salomon J, Simon B (1982) Courants de marée en Mer dIroise. Oceanol Acta 5(2):149-159

Mariette V, Thomas N, Cochin V, Guichoux Y, Ardhuin F (2006) Premiers résultats de l'expérience SURLITOP (Surveillance littorale opérationnelle)= First results of the SURLIIOP experiment (Operational littoral surveillance. Navigation 54(214):45-57

Mcintyre ME (1988) A note on the divergence effect and the Lagrangian-mean surface elevation in periodic water waves. Journal of Fluid Mechanics 189(-1):235

Mellor G, Blumberg A (2004) Wave Breaking and Ocean Surface Layer Thermal Response. Journal of physical oceanography 34

Mellor GL (2001) One-dimensional ocean surface layer modeling, a problem and a solution. J Phys Oceanogr 31(3):790-809

Mellor GL, Yamada T (1982) Development of a turbulence closure model for geophysical fluid problems. Reviews of geophysics and space physics 20(4):851-875

Muller H (2008) Etude de la circulation résiduelle lagrangienne en mer d'iroise / study of lagrangian residual circulation in the iroise sea. $\mathrm{PhD}$ thesis, Universite de Bretagne Occidentale.

Muller H, Dumas F, Blanke B, Mariette V (2007) High-resolution atmospheric forcing for regional oceanic model: the Iroise Sea. Ocean Dynamics 57(4):375-400

Muller H, Blanke B, Dumas F, Lekien F, Mariette V (2009) Estimating the Lagrangian residual circulation in the Iroise Sea. Journal of Marine Systems 78:17-36

Muller H, Blanke B, Dumas F, Mariette V (2010) Identification of typical scenarios for the surface Lagrangian Residual Circulation in the Iroise Sea. Journal of Geophysical Research 
Noh Y (1996) Dynamics of diurnal thermocline formation in the oceanic mixed layer. Journal of Physical Oceanography 26(10):2183-2195

Noh Y, Kim H (1999) Simulations of temperature and turbulence structure of the oceanic boundary layer with the improved near-surface process. Journal of Geophysical ResearchOceans 104(C7)

Orbi A, Salomon J (1988) Dynamique de marée dans le golfe normand-breton= Tidal dynamics in the vicinity of the Channel islands. Oceanologica acta 11(1):55-64

Paduan J, Rosenfeld L (1996) Remotely sensed surface currents in Monterey Bay from shore-based HF radar (Coastal Ocean Dynamics Application Radar). Journal of Geophysical Research 101(C9):20,669-20

Pavec M (2007) Instabilités barocline et paramétrique des courants de bord, application au front d'Ouessant. PhD thesis, Université de Bretagne Occidentale

Pavec M, Carton X, Swaters G (2005) Baroclinic instability of frontal geostrophic currents over a slope. Journal of Physical Oceanography 35:911-918

Pawlowicz R, Beardsley B, Lentz S (2002) Classical tidal harmonic analysis including error estimates in MATLAB using T_TIDE* 1. Computers \& Geosciences 28(8):929-937

Peters H, Gregg M, Toole J (1988) On the parameterization of equatorial turbulence. Journal of Geophysical Research 93(C2):1199-1218

Pingree RD, Holligan PM, Head RN (1977) Survival of dinoflagellate blooms in the western English Channel. Nature

Pollard RT, Millard Jr RC (1970) Comparison between observed and simulated windgenerated inertial oscillations. Deep Sea Research and Oceanographic Abstracts 17(4):813-821

Ralston DK, Stacey MT (2006) Shear and turbulence production across subtidal channels. Journal of Marine Research 64(1):147-171 
Rascle N (2007) Impact of waves on the ocean circulation (Impact des vagues sur la circulation oceanique). $\mathrm{PhD}$ thesis, $\mathrm{Ph}$. D. thesis, Universite de Bretagne Occidentale

Rascle N, Ardhuin F (2009) Drift and mixing under the ocean surface revisited: Stratified conditions and model-data comparisons. Journal of Geophysical Research-Oceans 114(C2):C02,016

Rascle N, Ardhuin F, Terray EA (2006) Drift and mixing under the ocean surface: A coherent one-dimensional description with application to unstratified conditions. Journal of geophysical research 111(C 3)

Roland A, et al (2008) Development of WWM II: Spectral wave modelling on unstructured meshes. PhD thesis, Ph. D. thesis, Technische Universit "at Darmstadt, Institute of Hydraulic and Water Resources Engineering

Smaoui H, Boughanim F, Chapalain G (2007) 1D vertical model for suspended sediment transport in turbulent tidal flow: Application to the English Channel. Computers \& geosciences 33(9):1111-1129

Stacey MW, Pond S (1997) On the Mellor-Yamada turbulence closure scheme: the surface boundary condition for q 2. Journal of Physical Oceanography 27(10):2081-2086

Stips A, Burchard H, Bolding K, Prandke H, Simon A, W

"uest A (2005) Measurement and simulation of viscous dissipation in the wave affected surface layer. Deep Sea Research Part II: Topical Studies in Oceanography 52(910):1133-1155

Stokes GG (1847) On the theory of oscillatory waves. Trans Camb Phil Soc 8(441):197-229 Sun Q, Guan C, Song J (2008) Wave breaking on turbulent energy budget in the ocean surface mixed layer. Chinese Journal of Oceanology and Limnology 26(1):9-13

Taylor KE (2001) Summarizing multiple aspects of model performance in a single diagram. J Geophys Res 106(D7):7183-7192 
Terray EA, Donelan MA, Agrawal YC, Drennan WM, Kahma KK, Williams AJ, Hwang PA, Kitaigorodskii SA (1996a) Estimates of kinetic energy dissipation under breaking waves. Journal of Physical Oceanography 26(5):792-807

Terray EA, Donelan MA, Agrawal YC, Drennan WM, Kahma KK, Williams III AJ, Hwang PA, Kitaigorodskii SA (1996b) Estimates of kinetic energy dissipation under breaking waves. J Phys Oceanogr 26:792-807

Tolman HL (2007) The 2007 release of WAVEWATCH III. In: Proceedings, 10th Int. Workshop of Wave Hindcasting and Forecasting, Hawaii

Umlauf L, Burchard H, Bolding K (2007) GOTM sourcecode and test case documentation Version 4.0

Xu Z, Bowen AJ (1994) Wave-and wind-driven flow in water of finite depth. Journal of Physical Oceanography 24(9):1850-1866 